Article

\title{
Investigating Trends in Streamflow and Precipitation in Huangfuchuan Basin with Wavelet Analysis and the Mann-Kendall Test
}

\author{
Yuzhuang Chen, Yiqing Guan *, Guangwen Shao and Danrong Zhang * \\ College of Water Resources and Hydrology, Hohai University, Xikang Road 1, Nanjing 210098, China; \\ cyz003@126.com (Y.C.); sgwen0327@126.com (G.S.) \\ * Correspondence: yiqingguan@hhu.edu.cn (Y.G.); danrong_zhang@hhu.edu.cn (D.Z.); \\ Tel.: +86-137-7663-3972 (Y.G.); +86-137-7067-2828 (D.Z.)
}

Academic Editor: Ataur Rahman

Received: 8 December 2015; Accepted: 18 February 2016; Published: 2 March 2016

\begin{abstract}
This study aims to investigate trends in streamflow and precipitation in the period 1954-2010 in a semiarid region of the Yellow River watershed, Huangfuchuan basin, China. The combination of the wavelet transform and different Mann-Kendall (MK) tests were employed to figure out the basic trends structure in streamflow and precipitation and what time scales are affecting the observed trends. The comparative analysis with five MK test methods showed that the modified MK tests with full serial correlation structure performed better when significant autocorrelations exhibited for more than one lag. Three criteria were used to determine the optimal smooth mother wavelet, the decomposition level and the extension mode used in the discrete wavelet transform (DWT) procedure. The first criteria referred to the relative error of the wavelet approximated component and the original series. The second one was the relative error of MK Z-values of approximation component and the original series. Additionally, a new criterion $(E r)$, based on the relative error of energy between the approximate component and the original series, was proposed in this study, with better performance than the previous two criteria. Further, a new powerful index, the energy of the hydrological time series, was proposed to verify the dominant periodic components for the observed trends. The analysis indicated that all monthly, seasonal and annual streamflow showed significant decreasing trends, while no significant trends were found in precipitation. Results from the DWT and MK tests revealed that the main factors influencing the trends in the monthly and seasonal series in Huangfuchuan watershed are intra-annual cycles, while the leading factors affecting the trends in the annual series are decadal events. Different driving factors (e.g., seasonal cycles, solar activities, etc.) related to the periodicities identified in these data types resulted in this discrepancy.
\end{abstract}

Keywords: trend analysis; wavelet transform; Huangfuchuan basin; Mann-Kendall test; streamflow; precipitation

\section{Introduction}

The processes that occur in the atmosphere and the earth's surface, such as precipitation and streamflow, are mainly driven by the energy exchange between the sun, the earth and the atmosphere [1]. The fifth IPCC assessment report [2] indicated the mean annual global air temperature exhibited a significant upward trend during the period from the 1880-2012, and the greatest increase was noted from 1979 to 2012 with a $0.25-0.27{ }^{\circ} \mathrm{C}$ increment per decade [3,4]. One of the most obvious effects aroused by climate warming and change is to intensify the hydrological cycle $[5,6]$. Changes in hydrological cycle may in turn affect the availability and quality of water resources, and the sustainability of water management, particularly in dry regions [7-10]. 
The Yellow River is considered to be China's mother river and the cradle of Chinese civilization, and it is a vital water source for hundreds of millions of people in the northern and north-western parts of China [11]. The Yellow River is $5464 \mathrm{~km}$ long with a basin area of 0.8 million $\mathrm{km}^{2}$, which is mainly comprised of arid and semi-arid environments [12]. The Huangfuchuan basin, an important semiarid watershed in the middle reaches of the Yellow River, was selected as a meso-scale catchment representative of the semiarid climates that predominate across the Yellow River watershed, in order to detect the effects of climate variability and change. A better understanding of climate variability and change on both a basin and regional scale is obviously critical to water management and sustainable ecological conservation of arid and semiarid regions. Many studies which consider both climate variability and change have centered on the assessments in hydro-climate parameters such as temperature, precipitation and streamflow [13-18]. Hydrological variables have been considered as useful indicators of how the climate has changed and varied over time, therefore, it is needful to research trends associated with hydrological events $[19,20]$.

The Mann-Kendall (MK) trend test has been widely used to trend detection in hydrology and climatology [15], due to its rank-based procedure with resistance to the influence of extreme values that facilitate the skewness variables [21-23]. But an obvious weakness of the MK test is that it is not accounting for the serial correlation which is very often seen in the hydro-climate data [24-26]. Studies have demonstrated that the presence of positive autocorrelation overestimated the significance of (both positive and negative) trends, while negative autocorrelation underestimated the significance of (both positive and negative) trends, if the autocorrelation is not considered [24,25]. In an effort to remove the influence of serial correlation on the MK test, the modified MK test with lag one and trend-free pre-whitening [25] and the modified MK test with variance correction were proposed and applied [24,26,27]. Gautam and Acharya (2012) [28] used trend-free pre-whitening to deal with serial and cross-correlation in detecting trends of streamflow in Nepal. However, Kumar et al. (2009) [29] found that consideration of only lag-1 autocorrelation is not sufficient to remove all significant serial correlation in the hydrological time series. Khaliq et al. (2009) [30] recommended the variance correction approach, because not only lag-1 but also higher lags are considered for serial correlation. However, Yue and Wang (2004) pointed out that the modified MK test with full autocorrelation structure is not powerful in the case that trend cannot be approximated by a linear trend [26].

Wavelet analysis is another effective way to analyze the time series owing to its capability of illustrating the localized characteristics of a series both in temporal and frequency domains [31-33]. Wavelet analysis has been extensively employed to determine the non-stationary trends and periodicities in the analysis of various hydrological and meteorological variables [34-37]. In order to better analyze the trends and the fluctuating patterns of the hydrological variables, the wavelet transform has been recently used in conjunction with the MK test [20,38-40]. Partal and Küçük (2006) [22] firstly co-utilized the wavelet transform and the original MK test to find which periodicities are mainly responsible for the trends of the annual total precipitation series and found that the trend analysis on detailed components of the precipitation time series resulting from the discrete wavelet transform (DWT) can clearly explain the trend structure of data. Nalley et al. (2012) [20] used DWT to analyze trends in streamflow and precipitation in Quebec and Ontario with the modified MK test proposed by Hirsch and Slack (1984), which accounts for seasonality and serial dependence. However, this modified MK test is not powerful when there is long-term persistence (with autoregressive parameter $>0.6$ ) or when there are less than 5 years' worth of monthly data [41].

When applying DWT to the decomposition of hydrologic time series, two critical issues, wavelet choice and decomposition level, should be confirmed firstly. When choosing wavelet, both the wavelet's properties and the hydrologic series' composition should be considered [42]. It is suggested that two conditions be followed, one is that the chosen wavelet must meet the regularity condition which is required for DWT [43]; another is that the appropriate wavelet should satisfy the need of accurately separating deterministic series from original series [42]. The Daubechies (db) wavelets not only meet these two conditions, but also are commonly used in hydro-meteorological wavelet-based 
studies [44-46]. The number of decomposition levels needs to be confirmed in order to avoid unnecessary levels of data decomposition. This number is affected by the number of data points and the mother wavelet used. The highest decomposition level should be in agreement with the data point where the last subsampling becomes smaller than the filter length [45]. The reason is that for signals with a finite length, convolution processes cannot perform at both ends of the signal since there is no information available outside these boundaries [47]. As a consequence, we need to make an extension at both edges. Border extensions that are frequently used are symmetrization, periodic extension and zero-padding-each of them has its defect, because of the discontinuities introduced at both ends of the signals $[45,47]$. In order to determine the appropriate mother wavelet, the decomposition levels and extension mode, two criteria have been proposed by de Artigas et al. (2006) and Nalley et al. (2012) [20,45], and which will be discussed in detail in Section 3.1.4.

The main purpose of this study is to investigate the possible trends and the basic structure of the trends in the mean streamflow and the total precipitation in Huangfuchuan watershed by analyzing its monthly, seasonal and annual time series through the wavelet transform and different MK tests. The trend analysis through different MK tests was examined at first for the selection of appropriate trend tests. Then the powerful trend tests were applied to determine the trends in the original data and the ones resulting from DWT. In the process of applying DWT, three criteria were used to determine the smooth mother wavelet, the decomposition levels, and the extension mode. In addition, a new criterion based on the relative error of energy between the original data and the approximation component decomposed from DWT was proposed and successfully employed in this study, and the usage of it was discussed in detail in Section 3.1.4. Finally, the trend structure in precipitation and streamflow in Huangfuchuan watershed was identified by the wavelet transform and powerful MK tests. Additionally, a new powerful index, the energy of the hydrological time series, was proposed in this study and used to confirm the dominant periodic components for the observed trends, and is discussed in detail in Sections 4.3-5.

\section{Study Area and Data}

The Yellow River consists of three major reaches, the upper, the middle and the lower reaches [48], and the middle reach of the Yellow River watershed contributes significantly to the total streamflow and sediment discharge of the Yellow River [49] The Huangfuchuan is a primary tributary of the right middle reach of the Yellow River with the length of the main channel $137 \mathrm{~km}$ and an average channel slope of $2.7 \%$ [50]. The Huangfuchuan watershed (as shown in Figure 1) is located at $110.3^{\circ} \sim 111.2^{\circ} \mathrm{E}$ and $39.2^{\circ} \sim 39.9^{\circ} \mathrm{N}$, with a catchment area of $3246 \mathrm{~km}^{2}$ that is characterized by a semi-arid continental climate. The basin's average precipitation and mean temperature from 1961 to 2000 were $388 \mathrm{~mm}$ and $7.5^{\circ} \mathrm{C}$, respectively [12]. The Huangfu gauging station started in 1954 with $3175 \mathrm{~km}^{2}$ of control area, which accounts for $98 \%$ of the area of the whole watershed. This area has complex geomorphological types including a feldspathic sandstone hilly-gully region, the loess hilly-gully region and the sanded loess hilly-gully region [51]. The Huangfuchuan basin is considered to be fairly vulnerable to climate change due to vegetation deterioration, soil erosion and land desertification [12,52].

Daily streamflow and precipitation observations from 1954 to 2010 for the Huangfu gauging station of the Huangfuchuan basin were provided by the Yellow River Conservancy Commission (YRCC). A large amount of work has been conducted by the YRCC to make sure of the quality of the data before they were released $[49,53]$. Stations with missing data of less than $3 \%$ can be considered as acceptable for hydrological research [8]. However, the Huangfu gauging station has fully complete observations over the chosen period. Therefore, the data used in this study is considered to be good quality. Monthly, seasonal and annual mean streamflow and total precipitation data (see Figure 2) were then collected and investigated in order to research short-term monthly variations (e.g., intra-annual and inter-annual cycles), seasonal cycles and long-term fluctuations such as multi-year, decadal and multi-decadal events [20]. 

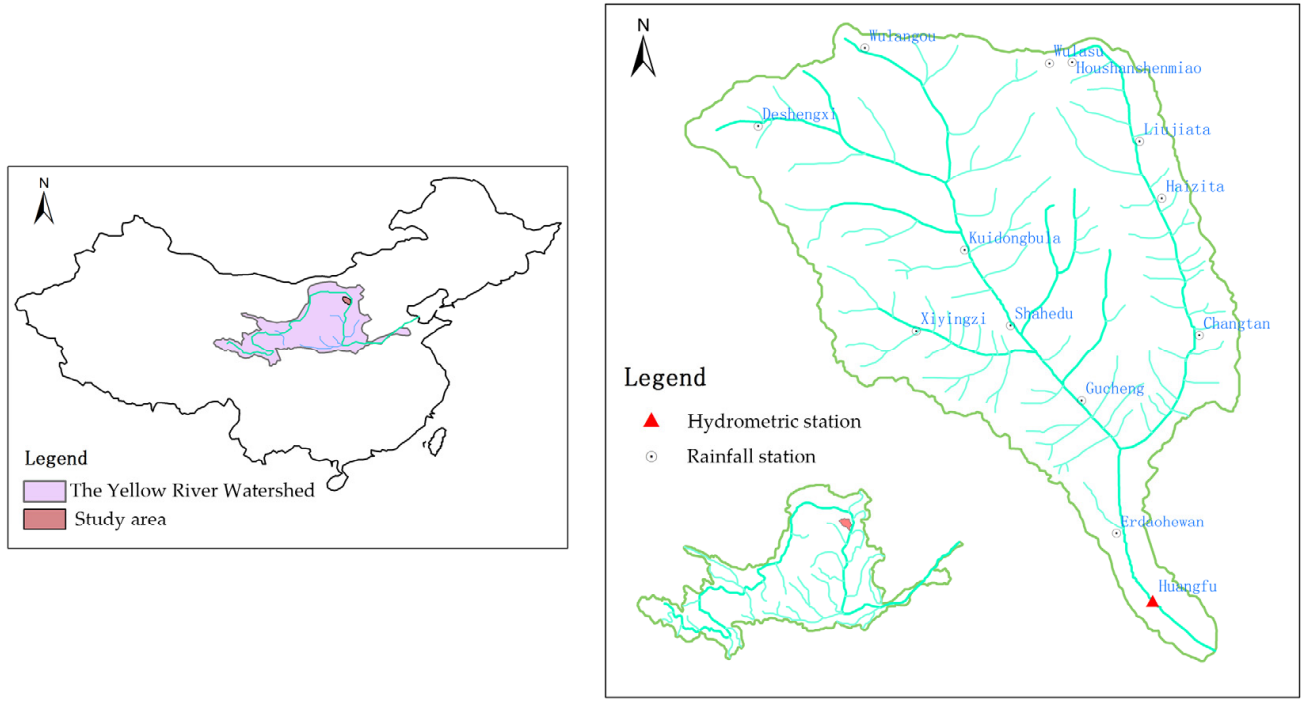

Figure 1. The location of the Huangfuchuan watershed.
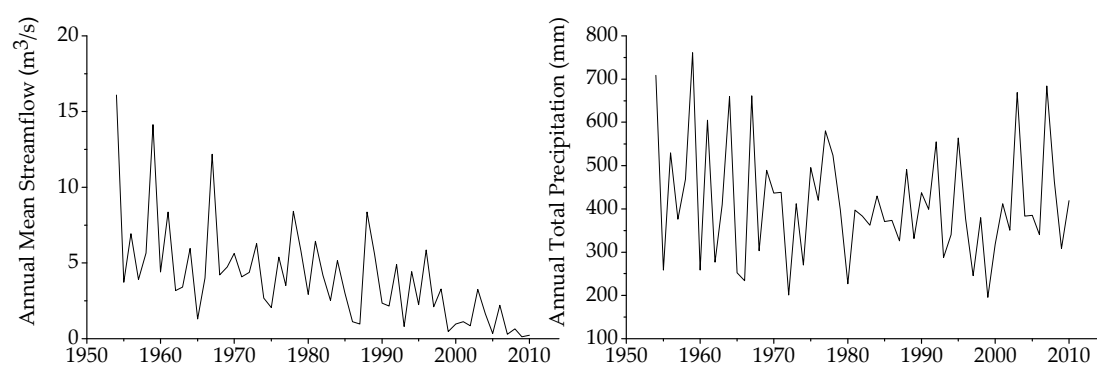

(a)

(b)
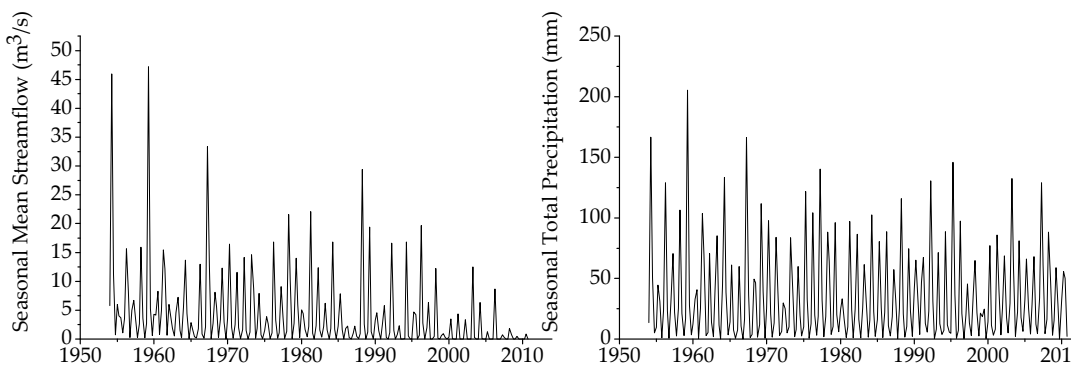

(c)

(d)

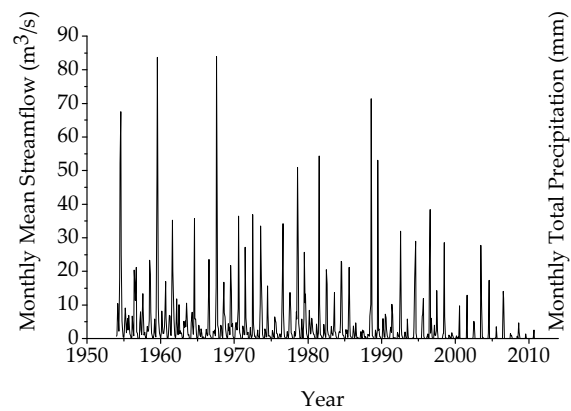

(e)

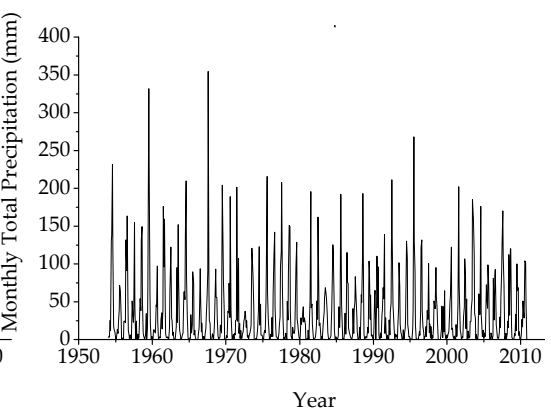

(f)

Figure 2. Monthly, seasonal and annual streamflow and precipitation plots of the study used. (a) annual streamflow; (b) annual precipitation; (c) seasonal streamflow; (d) seasonal precipitation; (e) monthly streamflow; (f) monthly precipitation. 
Burn and Elnur (2002) [19] considered that the length of the time series of at least 25 years was required in order to obtain an average statistic in assessing the trends of the streamflow. In addition, Partal (2010) [39] thought the length of the time series of 40 years was adequate for trend analysis studies. Kumar et al. (2009) [29] suggested that the same length of records should be used when analyzing trends of different variables to avoid misleading conclusions. Therefore, both the streamflow and precipitation of the same record length of 57 years for the period 1954-2010 would be adequate for the trend analysis in this study.

\section{Methodology}

\subsection{Wavelet Transforms (WTs)}

\subsubsection{Continuous Wavelet Transform (CWT)}

A discrete recording sequence existed in a continuous time series $x(t)$, and the wavelet function $\Psi(\eta)$ with a time variable $(\eta)$ is defined according to the reference $[20,22]$ :

$$
\Psi(\eta)=\Psi(s, \gamma)=\frac{1}{\sqrt{s}} \Psi\left(\frac{t-\gamma}{s}\right)
$$

where $\eta$ is the non-dimensional parameter, $t$ stands time, $\gamma$ is the translation factor (time shift) of the wavelet over the time series, and s represents the wavelet scale which ranges from 0 to $+\infty$. When $\gamma=0$ and $s=1, \Psi(t)$ represents the mother wavelet—all wavelets following this computation are the rescaled versions of the mother wavelet. In order to be acceptable as a wavelet, the function $\Psi(\eta)$ has to meet the condition of having a zero mean and be localized in time-frequency space [32]. As can be seen in Equation (1), when $s$ is less than 1, $\Psi(\eta)$ corresponds to a high-frequency function; when $s$ is greater than $1, \Psi(\eta)$ corresponds to a low-frequency function.

The wavelet coefficients $W_{\Psi}$ of CWT for the time series $x(t)$ are computed by using the convolution of $x(t)$ with the scaled and translated versions of the wavelet, $\Psi(\eta)[20,22]$ :

$$
W_{\Psi}(s, \gamma)=\frac{1}{\sqrt{s}} \int_{-\infty}^{\infty} x(t) \Psi^{*}\left(\frac{t-\gamma}{s}\right) d t
$$

where the asterisk symbol stands for the complex conjugate function. If the scale $(s)$ and translation $(\gamma)$ functions are smoothly changed along with extended time $t$, a scalogram can be produced from the calculation that indicates the amplitude of a specific scale and how it fluctuates over time [32].

The Morlet wavelet is widely used in natural time series applications as the basis wavelet function, which is defined as

$$
\Psi_{0}(\eta)=\pi^{-0.25} \mathrm{e}^{i \omega_{0} \eta} e^{-0.5 \eta^{2}}
$$

where $\omega_{0}$ is non-dimensional frequency and $\omega_{0}=6$ is used here to satisfy the admissibility condition. The advantage of the Morlet wavelet function provides a conductive definition of the signal in the spectral-space [54].

\subsubsection{Global Wavelet Spectrum}

Local spectrum can be measured by a vertical slice through a wavelet plot, the time-averaged wavelet spectrum, also called the global wavelet spectrum (GWS) [32], which is the average of this slice along the time-axis and can be expressed as

$$
\bar{W}^{2}(s)=\frac{1}{T} \sum_{t=0}^{T-1}|W(t, s)|^{2}
$$


where $T$ is the number of points in the time series. The smoothed Fourier spectrum approaches the GWS when the amount of necessary smoothing decreases with the increasing scale. Therefore, an unbiased and consistent estimation of the true power spectrum are provided by the GWS.

\subsubsection{Discrete Wavelet Transform (DWT)}

The DWT is normally based on the dyadic calculation of position and scale of a signal [55] and the form of DWT can be written as

$$
\Psi_{(a, b)}\left(\frac{t-\gamma}{s}\right)=s_{0}{ }^{-a / 2} \Psi\left(\frac{t-b \gamma_{0} s_{0}^{a}}{2^{a}}\right)
$$

where $\Psi$ represents the mother wavelet; $a$ and $b$ are integers that control the wavelet dilation (scale) and translation (time), respectively; $s_{0}$ is a fixed dilation step whose value is greater than 1 ; and $\gamma_{0}$ is the location parameter whose value is greater than zero. In general, for practical reasons, the parameters $s_{0}$ and $\gamma_{0}$ are 2 and 1, respectively [56]. This is the DWT dyadic grid arrangement. Supposing a discrete time series $x_{t}$, where $x_{t}$ occurs at a discrete time $t$, the wavelet coefficient for the DWT becomes

$$
W_{\Psi}(a, b)=2^{-a / 2} \sum_{t=0}^{N-1} x_{t} \Psi\left(\frac{t}{2^{a}}-b\right)
$$

where the wavelet coefficients $W_{\Psi}(a, b)$ are computed at scale $s=2^{a}$ and location $\gamma=2^{a} b$ which reveal the variation of signals at different scales and locations.

\subsubsection{Time Series Decomposition via DWT}

The multilevel 1-D wavelet decomposition function in MATLAB was used to accomplish the conventional discrete wavelet analysis of signals on each streamflow and precipitation time series. Since the trends of hydrologic time series are supposed to be gradual and represent slowly-changing processes, smoother wavelets should be better at detecting long-term time-varying behavior [23]. Therefore, smoother $\mathrm{db}$ wavelets (db5-db10) were then tried for each monthly, seasonal and annual dataset.

Based on de Artigas et al. (2006) [45], who analyzed monthly geomagnetic activity indices, the maximum decomposition level $\mathrm{L}$ is computed as

$$
L=\frac{\log \left(\frac{n}{2 v-1}\right)}{\log (2)}
$$

where $v$ represents the number of vanishing moments of a $\mathrm{db}$ wavelet and $\mathrm{n}$ denotes the number of data points in a monthly time series. In MATLAB, the number of vanishing moments for a $\mathrm{db}$ wavelet equals half of its starting filter length. For instance, db6 in MATLAB represents the Daubechies6 wavelet, which has a 12-point filter length. If someone uses db6 to analyze the signals, the value of $v$ is 6 .

For annual datasets with the length of 57 years, there were 684 data points for the monthly datasets and 228 for the seasonal datasets. Symmetrization, periodic extension and zero-padding were performed with signal extension in MATLAB, extending the monthly, seasonal and annual data points to 1024, 256, and 256, separately. A calculation based on Equation (7) indicates that the maximum monthly decomposition level values range from 5.8-6.8, 3.8-6.8 for seasonal level, and 3.8-4.8 for annual level. Since the decomposition levels should be a positive integer, the 6th and 7 th decomposition levels were used for each smooth $\mathrm{db}$ wavelet, 4th and 5th decomposition levels for seasonal data and 4th and 5th levels for annual data. 
Three criteria were applied to determine the smooth mother wavelet, decomposition levels and the extension mode in the data analysis of each data type and dataset. The first one is the mean relative error (MRE) that was proposed by de Artigas et al. (2006) [45], which was written as

$$
M R E=\frac{1}{n} \sum_{i=1}^{n} \frac{\left|a_{i}-x_{i}\right|}{\left|x_{i}\right|}
$$

where $x_{i}$ represents the original data value of an signal with a record length of $n$, and $a_{i}$ is the approximation value of $x_{i}$. However, this criteria cannot be used in the series that contains zero value, and there are zero values in the datasets that are used in this study. Therefore, the smallest mean absolute error $(M A E)$ was applied in this study as the first criteria to give a similar evaluation, which was computed as

$$
M A E=\frac{1}{n} \sum_{j=1}^{n}\left|a_{j}-x_{j}\right|
$$

The second one is the lowest approximation MK Z-value relative error (er) suggested by Nalley et al. (2012) [20], which was given as

$$
e_{r}=\frac{\left|Z_{a}-Z_{o}\right|}{\left|Z_{o}\right|}
$$

where $Z_{a}$ and $Z_{o}$ represent the MK $Z$-value of the last approximation for the decomposition level used and the original data, respectively.

The third criterion is the one proposed in this paper which is based on the energy of the series. Supposing a time series $x_{i}, n$ is the length of data record, the total energy of $x_{i}$ can be computed as below [42]

$$
E=\sum_{i=1}^{n}\left(x_{i}\right)^{2}
$$

Different combinations (of decomposition level, extension mode and mother wavelet) were examined that would generate the lowest approximation energy relative error $(E r)$. The computation of the relative error was done using the following equation:

$$
E r=\frac{\left|E_{a}-E_{o}\right|}{E_{o}}
$$

where $E_{o}$ is the total energy of the original series and $E_{a}$ is the total energy of the last approximation for the decomposition level used.

\subsection{Trend Analysis}

\subsubsection{The Mann-Kendall (MK) Trend Test}

In the test, the null hypothesis $H_{0}$ assumes that the deseasonalized data $\left(x_{1}, \ldots, x_{n}\right)$ denotes a sample of $n$ independent and randomly ordered variables. The alternative hypothesis $H_{1}$ of a two-sided test states that the distribution of $x_{i}$ and $x_{j}$ is not identical for all $i, j \leqslant n$ with $I \neq j$ [20].

The Mann-Kendall test statistic $S$ is calculated as:

$$
\begin{aligned}
& S=\sum_{i=1}^{n-1} \sum_{j=i+1}^{n} \operatorname{sgn}\left(x_{j}-x_{i}\right) \\
& \operatorname{sgn}(\theta)=\left\{\begin{array}{r}
1 \text { if } \theta>0 \\
0 \text { if } \theta=0 \\
-1 \text { if } \theta<0
\end{array}\right.
\end{aligned}
$$


For an independent data sample without tied values, the mean and variance of $S$ are given by:

$$
\begin{gathered}
E[S]=0 \\
\operatorname{Var}(S)=\frac{n(n-1)(2 n+5)}{18}
\end{gathered}
$$

If tied values are present in the sample, $\operatorname{Var}(S)$ is computed by:

$$
\operatorname{Var}(S)=\left[n(n-1)(2 n+5)-\sum_{i=1}^{n} t_{i}(i-1)(2 i+5)\right] / 18
$$

Then, the MK test statistic $Z$ for all those cases where $n$ is larger than 10 is given by [57]:

$$
Z=\left\{\begin{array}{ll}
\frac{S-1}{\sqrt{\operatorname{Var}(S)}} & S>0 \\
0 & S=0 \\
\frac{S+1}{\sqrt{\operatorname{Var}(S)}} & S<0
\end{array} \quad S=0\right.
$$

Therefore, the $H_{0}$ should be accepted if $|Z| \leqslant Z_{\alpha / 2}$ at the $\alpha$ level of significance in a two-sided test for trend. If $Z>0$, the time series has an upward trend and if $Z<0$, then there is a downward trend. Critical value $Z_{\alpha / 2}$ at $\alpha=5 \%$ significance level of trend test equals \pm 1.96 .

\subsubsection{Mann-Kendall Test with Trend-free Pre-whitening (TFPW)}

The TFPW procedure is proposed by Yue et al. (2002) [58] to detect a significant trend in a time series with significant serial correlation, including the following steps:

1. Calculate the lag-1 $(k=1)$ autocorrelation coefficient $\left(r_{1}\right)$ by:

$$
r_{k}=\frac{\sum_{t=1}^{n-k}\left(x_{t}-\bar{x}\right)\left(x_{t+k}-\bar{x}\right)}{\sum_{t=1}^{n}\left(x_{t}-\bar{x}\right)^{2}}
$$

If $\frac{\{-1-1.96 \sqrt{n-2}\}}{n-1} \leqslant r_{1} \leqslant \frac{\{-1+1.96 \sqrt{n-2}\}}{n-1}$, then the data are considered to be serial-independent at the $5 \%$ significant level and it is not necessary to conduct TFPW. Elsewhere data are assumed to be serial-correlated and TFPW is required.

2. The magnitude of trend in sample data is estimated by the Theil-Sen approach (TSA) $[59,60]$, the TSA slope $\beta$ is computed as:

$$
\beta=\operatorname{median}\left[\frac{x_{j}-x_{i}}{j-i}\right] \text { for all } i<j
$$

Then the series are detrened by using the following equation:

$$
x_{i}^{d}=x_{i}-\beta \times i
$$

3. Calculate the $r_{1}$ of the detrended series by using the Equation (18) and the AR(1) is removed from the detrended series to get a residual series by:

$$
x_{i}^{r}=x_{i}^{d}-r_{1} \times x_{i}^{d}
$$


4. The identified trend $(\beta \times i)$ is added back to the residual series to get a blended series by using the following

$$
x_{i}^{b}=x_{i}^{r}+\beta \times i
$$

Finally, the original MK test is applied to the blended series to assess the significance of the trend.

\subsubsection{Modified Mann-Kendall Test by Variance Correction}

The variance correction approach supposes that a correlated series is composed of $n$ data in which $n^{*}$ of them are uncorrelated. Hamed and Rao (1998) [24] and Yue and Wang (2004) [26] proposed modified variance $V(S)^{*}$ for computing the MK statistic Z:

$$
\begin{gathered}
V(S)^{*}=V(S) \cdot \frac{n}{n^{*}}=c f \cdot V(S) \\
c f_{1}=1+\frac{2}{n(n-1)(n-2)} \sum_{i=1}^{n-1}(n-i)(\mathrm{n}-i-1)(\mathrm{n}-i-2) \rho_{s}(i) \\
c f_{2}=1+2 \sum_{i=1}^{n-i}\left(1-\frac{i}{n}\right) \rho(i)
\end{gathered}
$$

where $c f_{1}$ is variance correction factor according to Hamed and Rao (1998) [24], $c f_{2}$ according to Yue and Wang (2004) [26], $\rho_{s}(i)$ is the lag- $i$ significant autocorrelation coefficient of time series ranks; $\rho(i)$ is the lag-i significant autocorrelation coefficient of time series. The values of $\rho_{s}(i)$ and $\rho(i)$ must be estimated from the detrended sample data and only significant values are used in Equations (24) and (25) since the insignificant values will have an adverse effect on the accuracy of the estimated variance of $S[24,26]$. The modified MK test calculated by using the $c f_{1}$ and $c f_{2}$ are referred as to MK1998 and MKDD, respectively.

The expression given by Kendall (1955) [24] in Equation (26) was used to transform rank autocorrelation to normalized data autocorrelation:

$$
\rho(i)=2 \sin \left(\frac{\pi}{6} \rho_{\mathrm{s}}(i)\right)
$$

Matalas and Langbein (1962) [61] provided a formula for calculating $n^{*}$ for the lag-1 autoregressive process:

$$
n^{*}=\frac{n}{1+2 \frac{\rho_{1}{ }^{n+1}-n \rho_{1}^{2}+(n-1) \rho_{1}}{n\left(\rho_{1}-1\right)^{2}}}
$$

When there is no trend exists, $r_{1}=\rho_{1}$ (Yue and Wang, 2004).

$$
c f_{3}=1+2 \frac{\rho_{1}{ }^{n+1}-n \rho_{1}^{2}+(n-1) \rho_{1}}{n\left(\rho_{1}-1\right)^{2}}
$$

The value of $\rho_{1}$ that is estimated form the detrended sample data and the modified MK test calculated by using the $c f_{3}$ is referred as to MKDD1.

\subsubsection{Sequential Mann-Kendall Test}

The progressive values $u(t)$ of the Mann-Kendall test were determined in order to see the change of trend with time. Similar to $Z$ value, $u(t)$ is a standardized variable with zero mean, unit standard deviation, and sequentially fluctuating behavior around the zero level [22]. 


\subsubsection{Determining the Dominant Periodic Components for the Observed Trends}

Two indexes, the closeness of the MK $Z$ values and the sequential MK graphs (between the individual periodic component and original time series), were employed to determine the most influential periodic component(s) for trends observed in a hydrological time series [20,22,39]. Since the results of the MK trend analysis on periodic (or detailed) component(s) can be better interpreted with their respective approximation added [20], therefore, in this study: (1) the MK value for each of the detailed components with respective approximation was compared to the MK $Z$ value of the original time series to see if they are close (even if the values were not significant); (2) the sequential MK graphs of each detailed component with the respective approximation were examined in comparison with the original time series to see their proximity. If a detailed component (with the approximation added) meets the two requests, this detailed component could be considered as the most dominant periodic component for the observed trends. In addition to the $M K Z$ value and the sequential MK graphs, a new index based on the energy of the hydrological time series was proposed in this study and also used to verify the dominant periodic components for the observed trends.

\section{Results and Discussion}

\subsection{Mann-Kendall Analysis}

Streamflow and precipitation time series (from the beginning of 1954 to the end of 2010) in Huangfuchuan hydrologic station were collected for the analysis of trends. Table 1 summarized the lag-1 autocorrelation coefficients or the autocorrelation functions (ACFs) and MK $Z$ values (using the five methods mentioned earlier) of the flow and precipitation with regards to the monthly, seasonal and annual series. All those three series showed significant downward trends using different MK trend test methods. Monthly and seasonal total precipitation series exhibited weak upward trends; while annual total precipitation series showed poor downward trends.

Table 1. Lag-1 autocorrelation functions (ACFs) and MK values (using different MK methods) of the original monthly, seasonal, and annual streamflow and precipitation series (MS: monthly streamflow; SS: seasonal streamflow; AS: annual streamflow; MP: monthly precipitation; SP: seasonal precipitation; AP: annual precipitation).

\begin{tabular}{ccccccc}
\hline Type & ACF & MK & TFPW & MK1998 & MKDD & MKDD1 \\
\hline MS & $0.399^{*}$ & $\mathbf{- 1 3 . 1 7 9}$ & $\mathbf{- 1 2 . 4 1 0}$ & $-\mathbf{5 . 5 0 3}$ & $-\mathbf{4 . 0 2 5}$ & $-\mathbf{8 . 7 7 9}$ \\
SS & 0.065 & $-\mathbf{7 . 6 2 4}$ & $-\mathbf{7 . 7 6 4}$ & $-\mathbf{4 . 0 5 5}$ & $\mathbf{- 3 . 1 8 8}$ & $\mathbf{- 7 . 5 7 8}$ \\
AS & 0.166 & $\mathbf{- 5 . 2 3 9}$ & $\mathbf{- 5 . 3 7 6}$ & $\mathbf{- 5 . 2 3 9}$ & $\mathbf{- 5 . 2 3 9}$ & $\mathbf{- 6 . 3 1 2}$ \\
MP & $0.482^{*}$ & $\mathbf{0 . 2 0 2}$ & $\mathbf{0 . 3 8 0}$ & $\mathbf{0 . 2 2 8}$ & $\mathbf{0 . 1 9 3}$ & $\mathbf{0 . 1 2 0}$ \\
SP & -0.051 & 0.168 & 0.107 & 0.086 & 0.067 & 0.176 \\
AP & $-0.266^{*}$ & -0.902 & -0.984 & -1.286 & -1.344 & -1.196 \\
\hline
\end{tabular}

Notes: * indicates significant lag-1 serial correlation at $\alpha=5 \%$; significant trend ( $95 \%$ confidence level) results are shown in bold letters.

It is documented that the presence of positive autocorrelation overestimated the significance of (both positive and negative) trends, while negative autocorrelation underestimated the significance of (both positive and negative) trends, if the autocorrelation is not considered [24,58]. As can be seen, all monthly series for both streamflow and precipitation exhibited significant lag-1 positive autocorrelation. The absolute MK $Z$ values of monthly mean streamflow based on the modified MK test methods decreased to some degree ( $6 \%$ or more) compared to the original MK, in which TFPW and MKDD1 exhibited less decrease than MK1988 and MKDD. For monthly total precipitation, there is a decrease in the MK $Z$ values of MKDD and MKDD1 compared to the original MK, while there is an increase in TFPW and MK1998 compared to the original MK. The differences are considered as very small since there are no significant trends found in all these methods. Annual total precipitation 
showed lag-1 negative autocorrelation. Comparing to the original MK, the absolute MK $Z$ values based on the modified MK test methods increased to some degree, where TFPW and MKDD1 had a relatively smaller increase compared to MK1988 and MKDD. Seasonal and annual mean streamflow series and seasonal total precipitation series exhibited no significant autocorrelation. The results of different types of data from TFPW and MKDD1 were very similar to the original MK. The results of annual mean streamflow from MK1998 and MKDD were almost the same as the original MK. However, within seasonal mean streamflow and seasonal total precipitation series, the MK $Z$ values from MK1998 and MKDD were significantly different from the original MK.

In general, the four modified Mann-Kendall tests limited the impacts of the autocorrelation on the trend assessment of the time series to a certain extent. However, MK1998 and MKDD had significant different test results compared to TFPW and MKDD1. This is mainly attributed to the fact that TFPW and MKDD1 only account for lag-1 autocorrelation while MK1988 and MKDD take all significant $\rho$ values into consideration. The correlograms of monthly, seasonal and annual can be seen in Figure 3. As it is shown, those data have significant autocorrelations extending beyond the first lag. Obviously, consideration of only lag-1 autocorrelation (for TFPW and MKDD1) is not sufficient to remove all significant serial correlation in the data series. It is also found that there is a presence of annual cycles with repeated ACF values at about every 12th lag for monthly series and every 4th lag for seasonal series. This may explain why the MK Z values of seasonal mean streamflow and seasonal total precipitation series based on MK1998 and MKDD differed significantly from the original MK. Although a time series exhibited no significant lag-1 autocorrelation, applying the original MK may obtain the wrong results because of the presence of annual cycles. Thus, the modified MK tests (MK1998 and MKDD) that consider full serial correlation structure should be used even though there is no significant lag-1 autocorrelation due to the annual cycles.

In this study, significant autocorrelations could exhibit for more than just one lag in a lot of time series (see Section 4.3.1), therefore, the modified MK tests (MK1998 and MKDD) that consider full serial correlation structure were recommended here. However, based on the later analysis on monthly and annual total precipitation, the original MK test was also applied due to the limitation of the modified MK test for full serial correlation structure. Therefore, these three MK tests were employed to examine the trends in the original time series and those resulting from the wavelet decomposition.

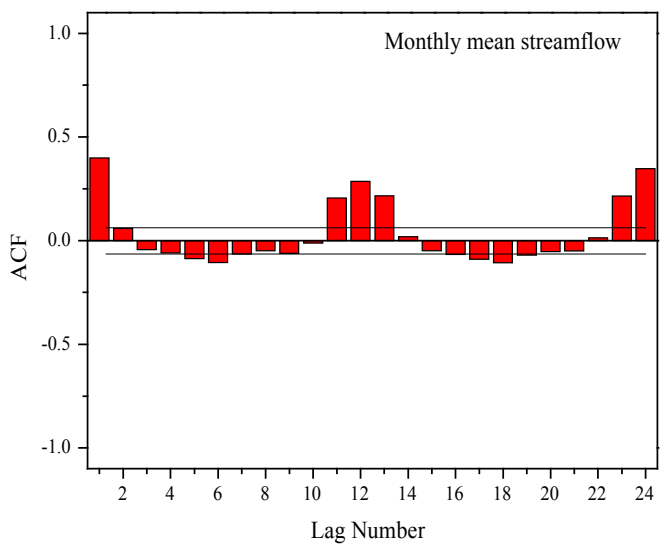

(a)

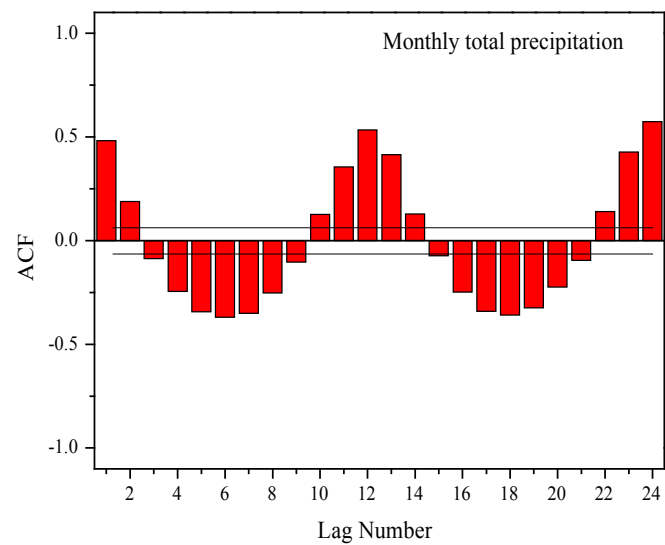

(b)

Figure 3. Cont. 


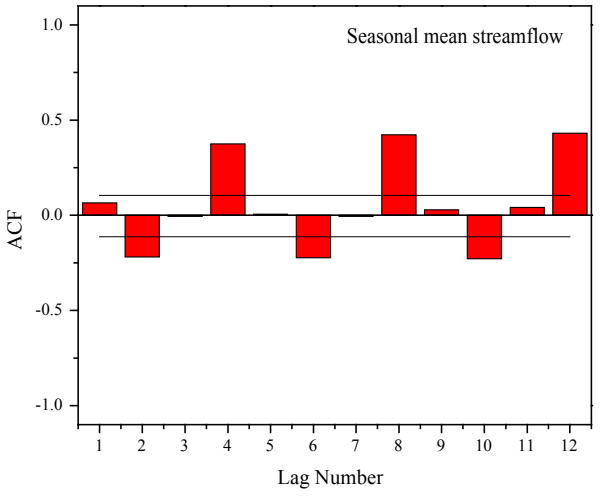

(c)

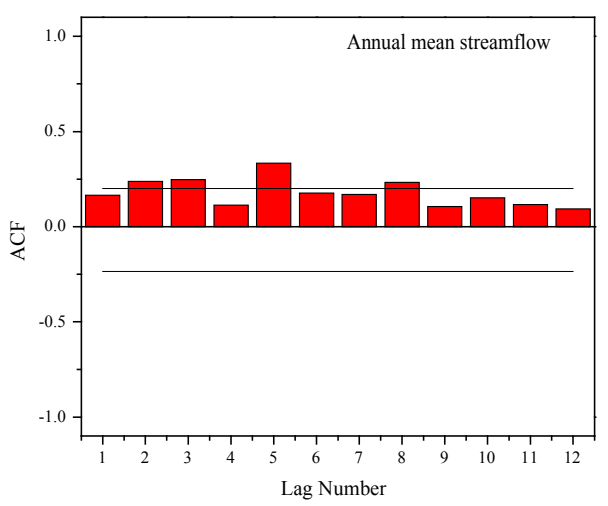

(e)

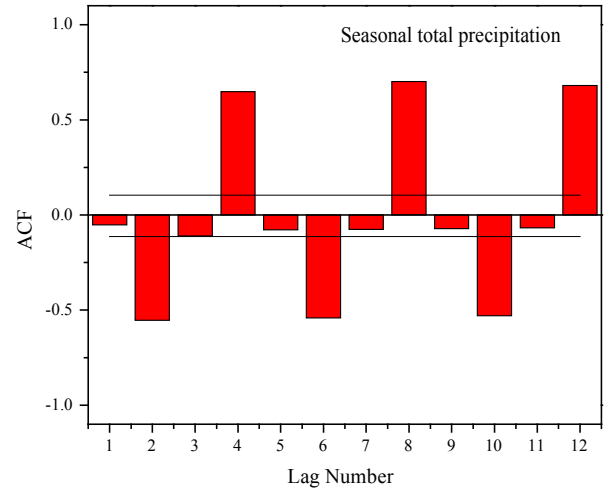

(d)

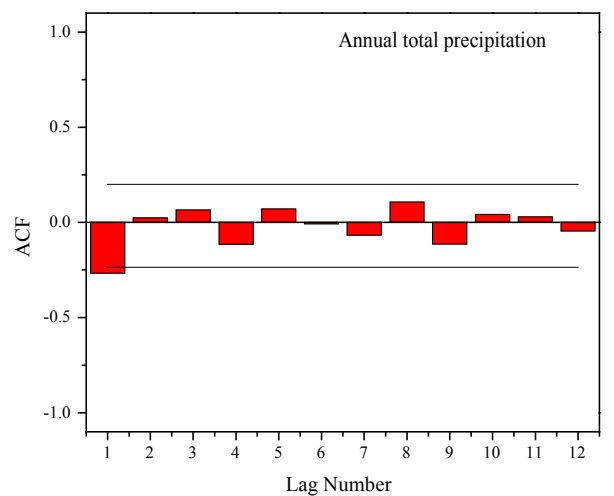

(f)

Figure 3. The correlograms of monthly, seasonal and annual series. The upper and lower solid lines represents the confidence intervals (95\% confidence level). (a) monthly streamflow; (b) monthly precipitation; (c) seasonal streamflow; (d) seasonal precipitation; (e) annual streamflow; (f) annual precipitation.

\subsection{Decomposition via DWT}

Three criteria were applied to determine the smooth mother wavelet, the decomposition levels and the extension mode, which were used in the data analysis for each data type and dataset. The results of monthly streamflow are (see Table 2) showing significant differences among the three criteria. The minimum $M A E$ value (4.577) corresponds to the six decomposition levels, zero-padding extension and $\mathrm{db} 5$ wavelet. The minimum er value (0.516) responds to the seven decomposition levels, zero-padding extension and $\mathrm{db} 7$ wavelet. The minimum Er value (0.792) corresponds to the seven decomposition levels, symmetrization extension and db5 wavelet. It is interesting to find that at the same level of decomposition, the extension modes were symmetrical extension, periodic extension and zero-padding extension, accordingly, at the same time, the values of Er were increasing (Figure 4). In other words, the symmetrical extension mode is more suitable than the other two extension modes to expand the hydrological time series according to the Er criterion. Further analysis of other types of data also indicated that the symmetrical extension mode is most applicable to broaden hydrological time series, followed by the periodic extension mode and the zero-padding extension mode, which performs worst based on the Er criterion. Similarly, Kharitonenko also argued that the point-symmetric extension method performs better than other methods [62]. In addition, according to the comparison of linear fit of the original series and the approximate component decomposing from different db types in the three extension modes, we found that the ways of boundary extension were symmetric extension, period extension and zero-padding extension in sequence, and the degree of proximity was overall 
descending, for example, total annual precipitation (Figure 5); similar results were also found in other types of data which are mainly consistent with the conclusions obtained from the criterion of Er.

Table 2. MAE, er, and $E r$ of monthly mean flow series (sym: symmetrization extension; per: periodic extension; zpa: zero-padding extension).

\begin{tabular}{|c|c|c|c|c|c|c|c|c|}
\hline $\begin{array}{l}\text { Extension } \\
\text { Mode }\end{array}$ & $\begin{array}{l}\text { Decomposition } \\
\text { Levels }\end{array}$ & Criterion & db5 & $\mathrm{db} 6$ & $\mathrm{db} 7$ & $\mathrm{db} 8$ & db9 & db10 \\
\hline \multirow{6}{*}{ sym } & \multirow{3}{*}{$L=6$} & $M A E$ & 4.637 & 4.658 & 4.627 & 4.632 & 4.643 & 4.638 \\
\hline & & er & 1.772 & 1.613 & 1.723 & 2.005 & 1.643 & 1.783 \\
\hline & & $E r$ & 0.798 & 0.803 & 0.805 & 0.799 & 0.8 & 0.805 \\
\hline & \multirow{3}{*}{$L=7$} & $M A E$ & 4.667 & 4.68 & 4.642 & 4.634 & 4.66 & 4.666 \\
\hline & & er & 1.425 & 0.863 & 1.295 & 1.687 & 0.990 & 0.616 \\
\hline & & $E r$ & 0.792 & 0.798 & 0.812 & 0.805 & 0.795 & 0.802 \\
\hline \multirow{6}{*}{ per } & \multirow{3}{*}{$L=6$} & $M A E$ & 4.672 & 4.679 & 4.697 & 4.699 & 4.677 & 4.684 \\
\hline & & er & 2.287 & 2.732 & 3.252 & 2.628 & 2.297 & 1.759 \\
\hline & & $E r$ & 0.811 & 0.817 & 0.813 & 0.808 & 0.812 & 0.816 \\
\hline & \multirow{3}{*}{$L=7$} & $M A E$ & 4.799 & 4.814 & 4.736 & 4.736 & 4.792 & 4.806 \\
\hline & & er & 1.352 & 1.793 & 1.142 & 1.142 & 1.787 & 1.505 \\
\hline & & $E r$ & 0.82 & 0.811 & 0.829 & 0.829 & 0.82 & 0.813 \\
\hline \multirow{6}{*}{ zpa } & \multirow{3}{*}{$L=6$} & $M A E$ & 4.577 & 4.6 & 4.606 & 4.591 & 4.587 & 4.604 \\
\hline & & er & 1.907 & 1.131 & 1.469 & 1.656 & 1.715 & 1.341 \\
\hline & & $E r$ & 0.816 & 0.819 & 0.817 & 0.813 & 0.816 & 0.819 \\
\hline & \multirow{3}{*}{$L=7$} & $M A E$ & 4.577 & 4.606 & 4.616 & 4.595 & 4.581 & 4.604 \\
\hline & & er & 0.922 & 0.747 & 0.516 & 0.583 & 1.066 & 0.624 \\
\hline & & $E r$ & 0.828 & 0.823 & 0.829 & 0.834 & 0.829 & 0.824 \\
\hline
\end{tabular}

Notes: The minimum $M A E$, er, and $E r$ are indicated in bold format.

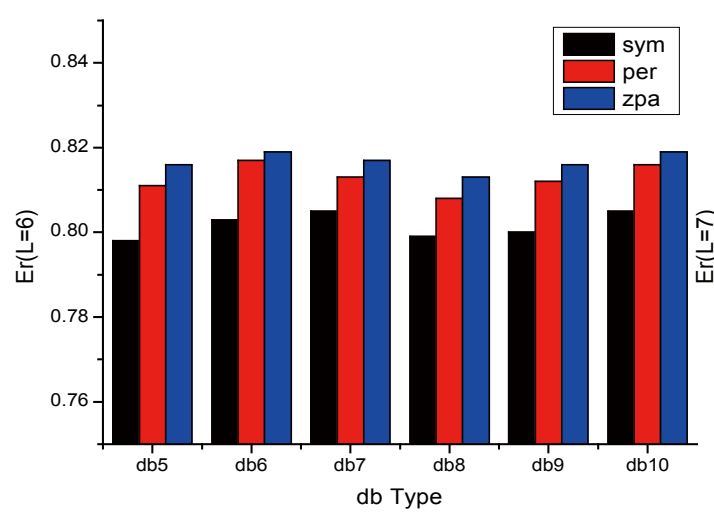

(a)

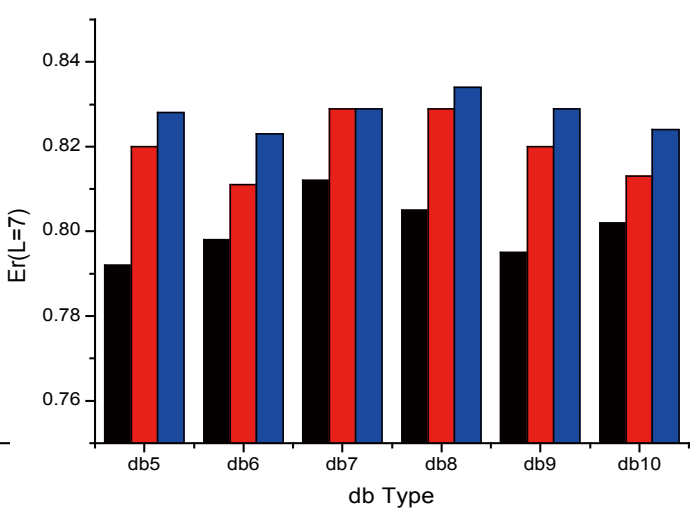

(b)

Figure 4. Er values of monthly mean streamflow series with different extension mode in six and seven levels (sym: symmetrization extension; per: periodic extension; zpa: zero-padding extension). (a) $\mathrm{L}=6$; (b) $\mathrm{L}=7$.

Further, the selected results by three criteria are given in Table 3 directly, instead of listing all calculated values of other types of data, due to limited space. As shown, results vary from one criterion to another. Determining the best criterion with higher accuracy and precision will facilitate the utilization of DWT for the decomposition results which depend on extension mode, decomposition level, and selected wavelet function [42]. All three criteria described the proximity between original time series and the approximate components that were obtained through the decomposition of the original series, therefore this study made the linear fit of original series and approximate components in order to compare the degree of proximity and evaluate the best optional criterion, as shown in Figure 6. Linear-fitting trend lines of approximate components obtained from the criterion that is 
proposed in this study matched the trend line of the original series to the largest extent, except for the annual total precipitation.

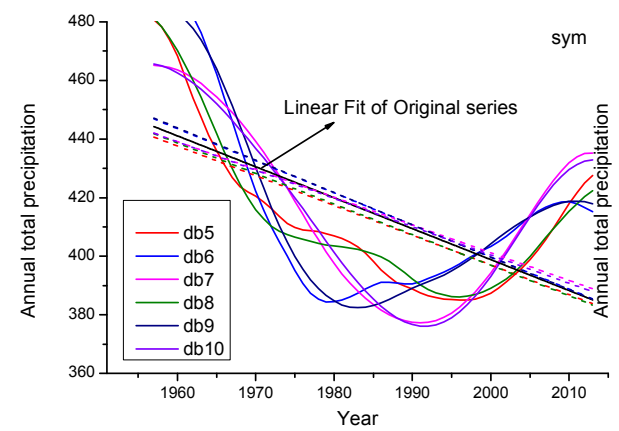

(a)

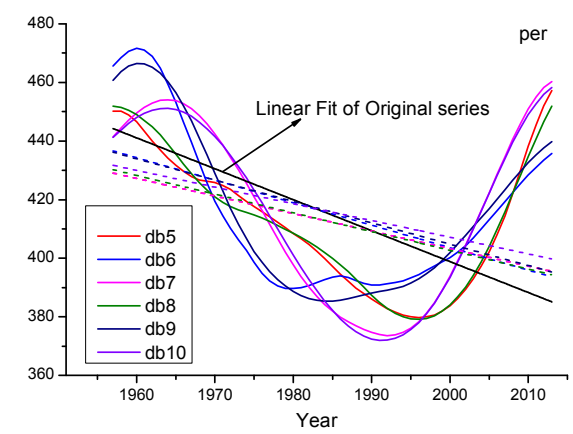

(b)

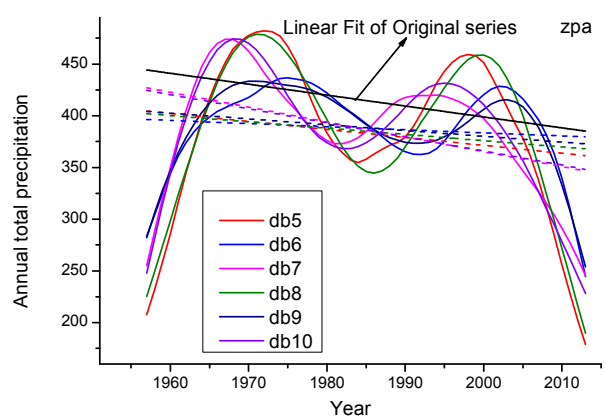

(c)

Figure 5. Linear fit of original series and approximate components of annual total precipitation series in three extension modes (sym: symmetrization extension; per: periodic extension; zpa: zero-padding extension) with the decomposition level $L=4$. The dash lines are the linear fits of the approximate components decomposing from different db types. (a) sym; (b) per; (c) zpa.

Table 3. The results of extension mode, decomposition levels and db type that were used in DWT of monthly, seasonal and annual flow and precipitation series in the three criteria (MS: monthly streamflow; SS: seasonal streamflow; AS: annual streamflow; MP: monthly precipitation; SP: seasonal precipitation; AP: annual precipitation; sym: symmetrization extension; per: periodic extension; zpa: zero-padding extension).

\begin{tabular}{|c|c|c|c|c|}
\hline Criterion & Data Type & Extension Mode & Decomposition Levels & db Type \\
\hline \multirow{6}{*}{$M A E$} & MS & zpa & 6 & db5 \\
\hline & MP & zpa & 7 & db5 \\
\hline & SS & zpa & 4 & $\mathrm{db} 7$ \\
\hline & $\mathrm{SP}$ & zpa & 5 & $\mathrm{db} 7$ \\
\hline & AS & zpa & 4 & $\mathrm{db} 6$ \\
\hline & $\mathrm{AP}$ & sym & 4 & $\mathrm{db} 5$ \\
\hline \multirow{6}{*}{ er } & MS & zра & 7 & $\mathrm{db} 7$ \\
\hline & MP & per & 6 & $\mathrm{db} 6$ \\
\hline & SS & sym & 5 & $\mathrm{db} 10$ \\
\hline & SP & per & 4 & $\mathrm{db} 10$ \\
\hline & AS & zpa & 4 & $\mathrm{db} 7$ \\
\hline & $\mathrm{AP}$ & per & 4 & $\mathrm{db} 10$ \\
\hline \multirow{6}{*}{ Er } & MS & sym & 7 & db5 \\
\hline & MP & per & 6 & $\mathrm{db} 8$ \\
\hline & SS & sym & 4 & db5 \\
\hline & $\mathrm{SP}$ & sym & 4 & $\mathrm{db} 9$ \\
\hline & AS & sym & 4 & $\mathrm{db} 9$ \\
\hline & $\mathrm{AP}$ & per & 5 & $\mathrm{db} 8$ \\
\hline
\end{tabular}




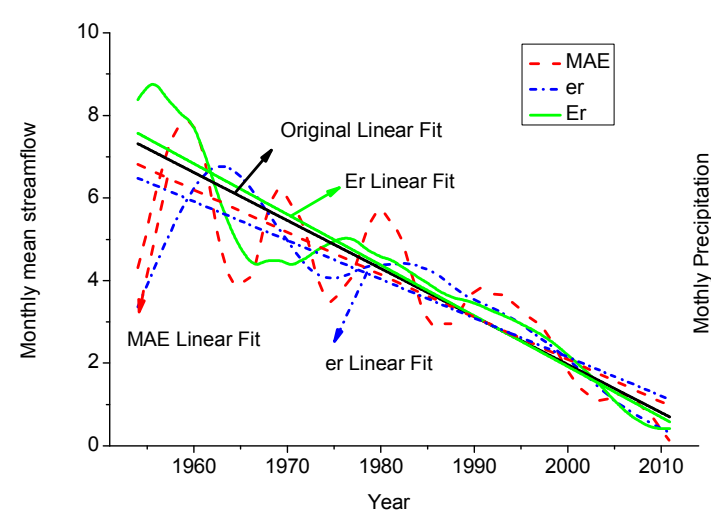

(a)

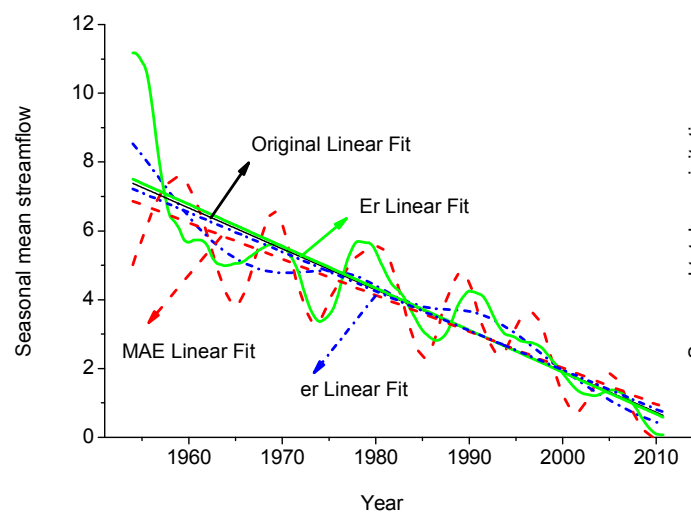

(c)

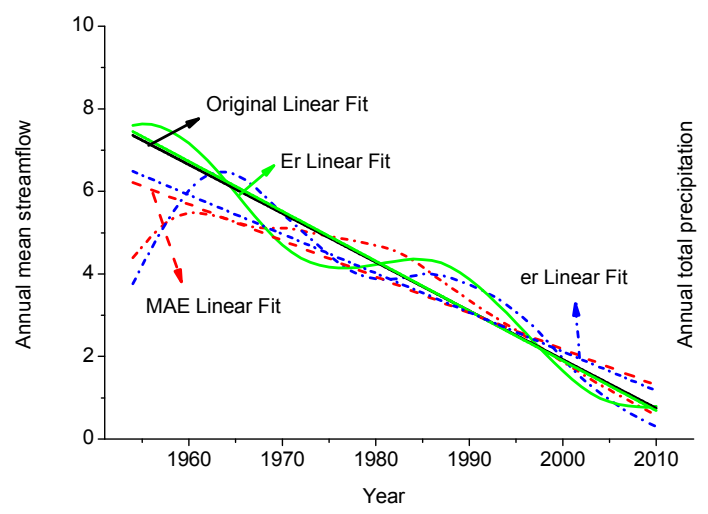

(e)

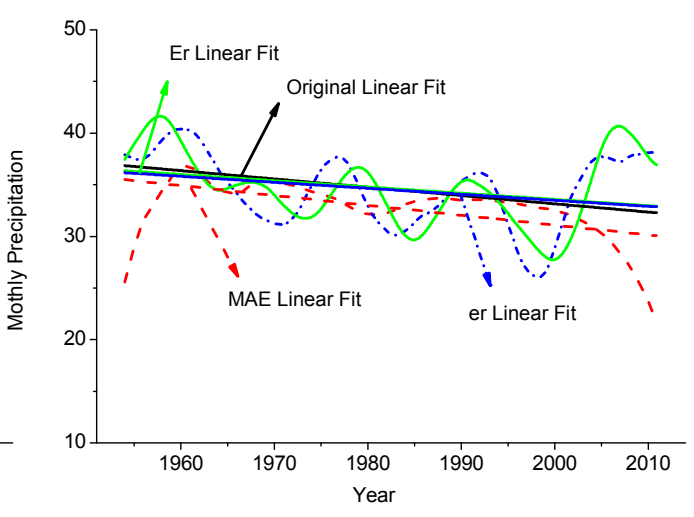

(b)

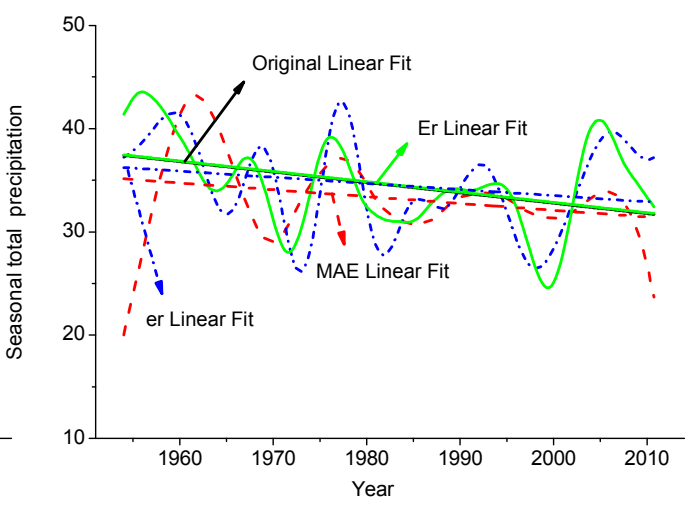

(d)

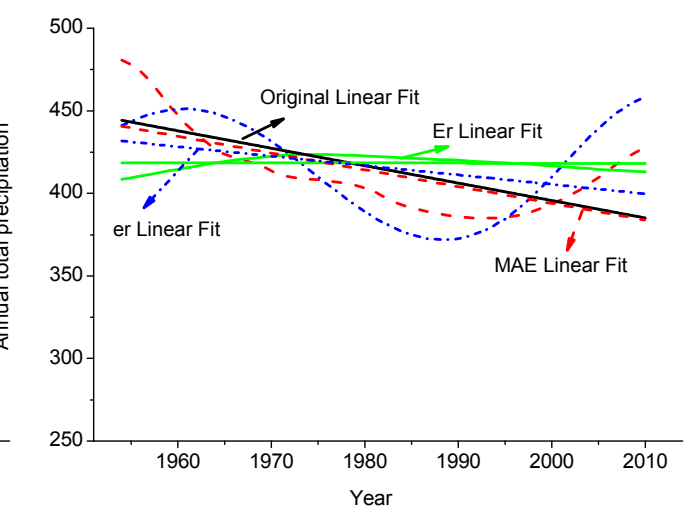

(f)

Figure 6. Linear fit of original series and approximate components of monthly, seasonal and annual streamflow and precipitation series in the three criteria. (a) monthly streamflow; (b) monthly precipitation; (c) seasonal streamflow; (d) seasonal precipitation; (e) annual streamflow; (f) annual precipitation.

Overall, the criterion $E r$ in this study performed with higher accuracy and precision in comparison to the other two criteria, therefore, the selected results were used in DWT (see Table 3). 


\subsection{Decomposition and Analysis of Monthly Data}

The monthly mean flow and total precipitation time series were decomposed into seven and six lower resolution levels via the DWT approach, respectively. The detail components represent the 2-month periodicity (D1), 4-month periodicity (D2), 8-month periodicity (D3), 16-month periodicity (D4), 16-month periodicity (D4), 32-month periodicity (D5), 64-month periodicity (D6) and 128-month periodicity (D7). A6 and A7 represent the approximate components at the sixth and seventh level of decomposition, respectively. The application of the discrete wavelet transform on the monthly flow and precipitation are shown in Figures 7 and 8 respectively. The lower detailed levels with higher frequencies represent the rapidly changing component of the series; on the contrary, higher detailed levels with lower frequencies represent the slowly changing component, such as approximation component A7 in Figure 7 and A6 in Figure 8.

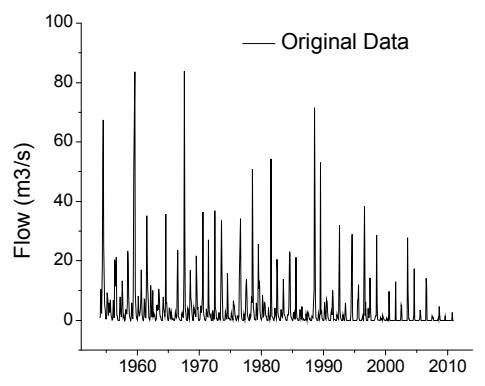

(a)

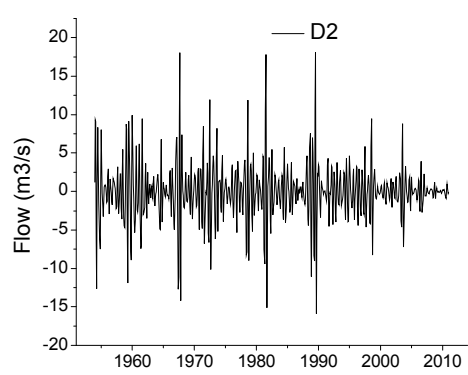

(d)

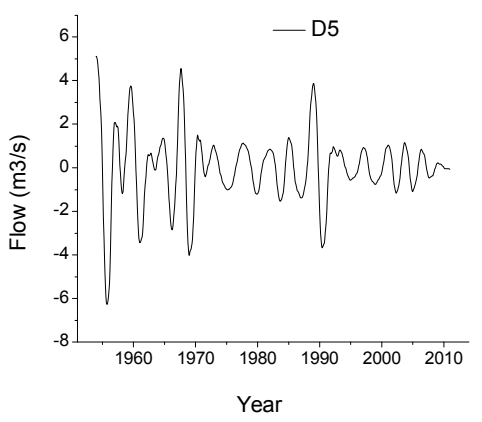

(g)

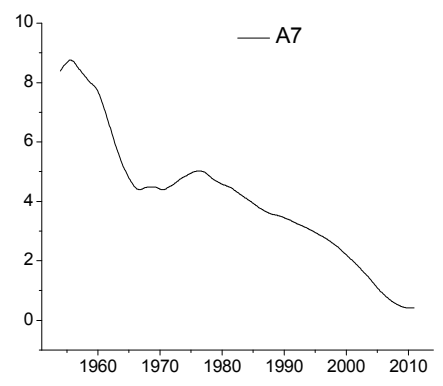

(b)

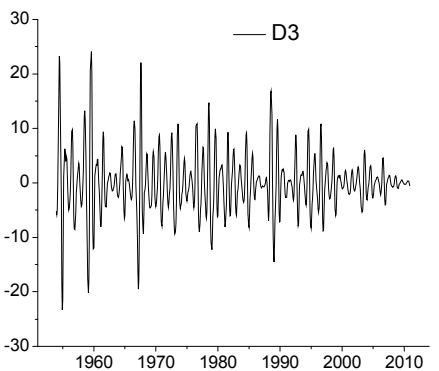

(e)

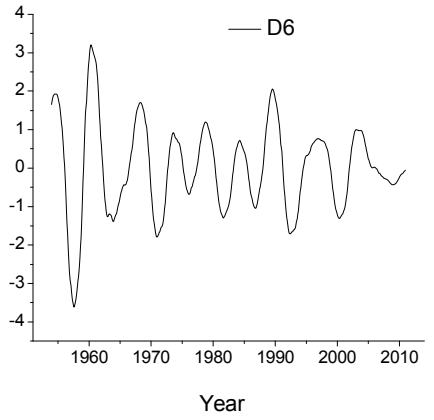

(h)

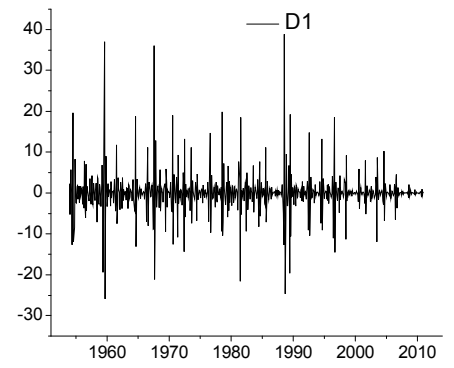

(c)

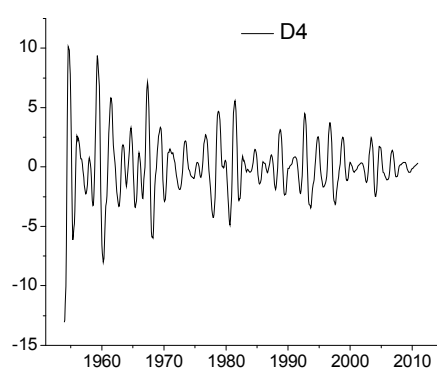

(f)

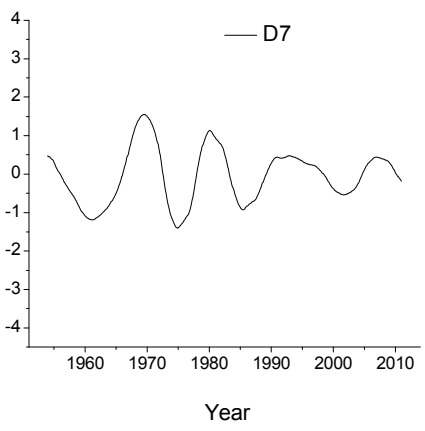

(i)

Figure 7. Original monthly mean streamflow series and its approximation (A7) and detail components (D1-D7) decomposed via DWT. (a) original data; (b) A7; (c) D1; (d) D2; (e) D3; (f) D4; (g) D5; (h) D6; (i) D7. 


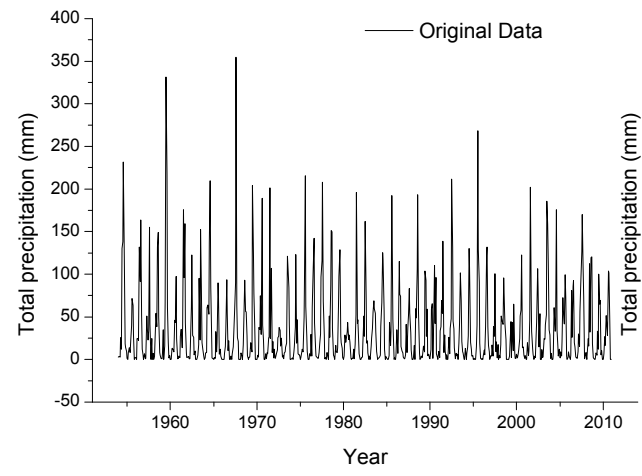

(a)

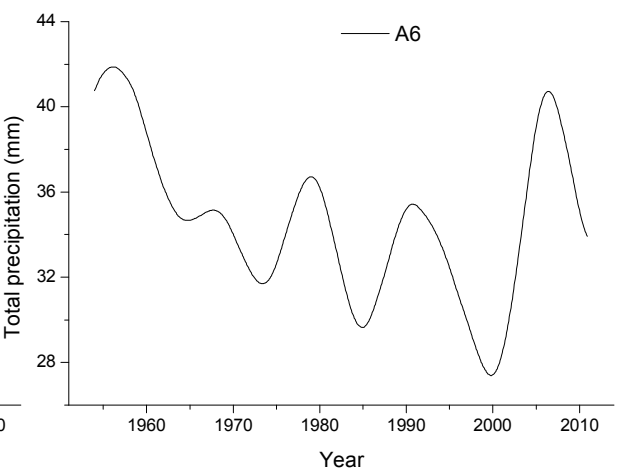

(b)

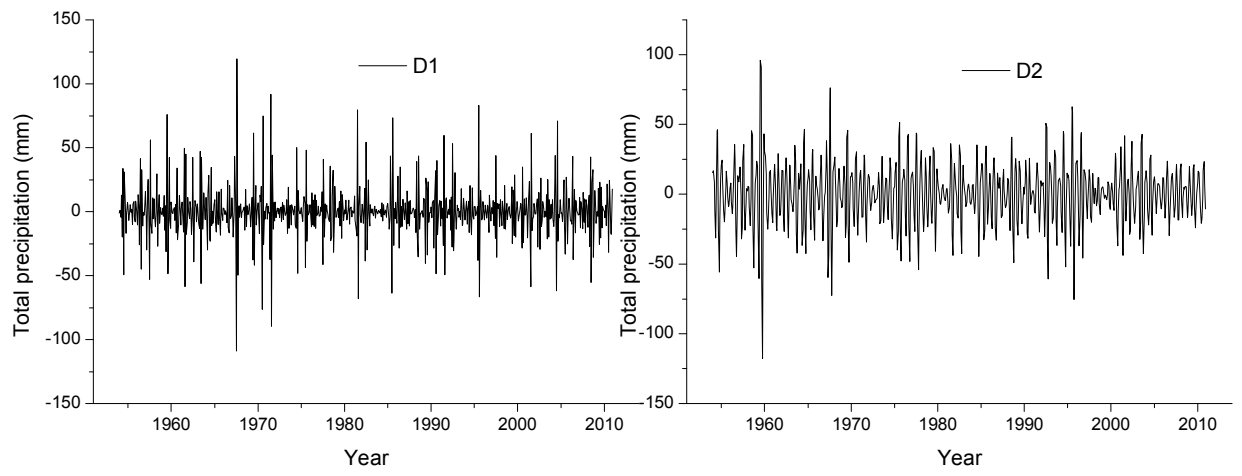

(c)

(d)
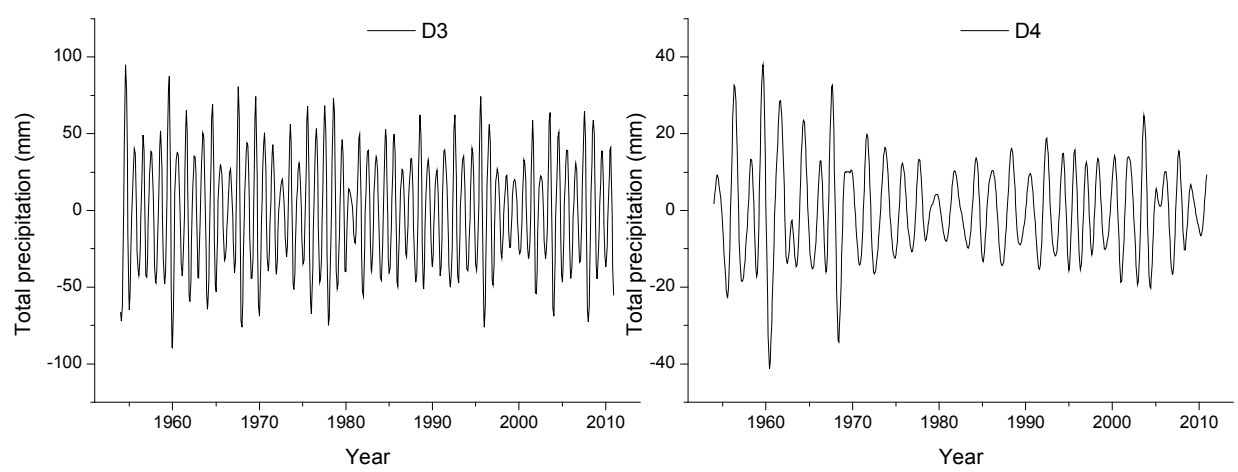

(e)

(f)

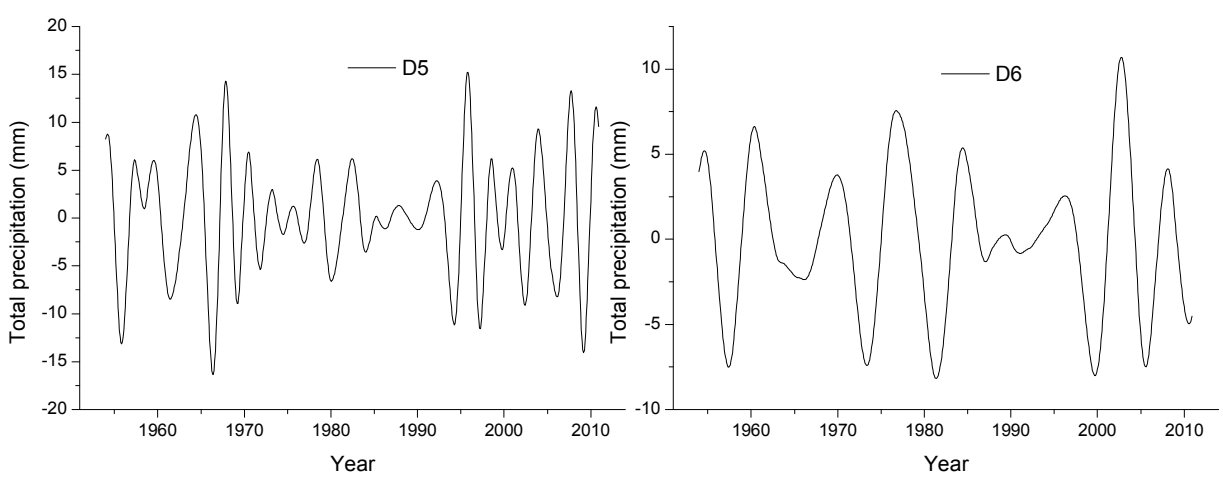

(g)

(h)

Figure 8. Original monthly precipitation series and its approximation (A6) and detail components (D1-D6) decomposed via DWT. (a) original data; (b) A6; (c) D1; (d) D2; (e) D3; (f) D4; (g) D5; (h) D6. 


\subsubsection{Monthly Mean Streamflow Series}

The results of the trend analysis in the original and the wavelet components of the monthly mean flow series using three MK trend tests are shown in Table 4. As can be seen, the correlation coefficients of the detail components, approximations and different combinations are very high, with most of the values greater than 0.6. The modified MK test proposed by Hirsch and Slack (1984), which accounts for seasonality and serial dependence, was not applied in this study because this method is not powerful when there is long-term persistence (with autoregressive parameter $>0.6$ ) [41]. In addition, significant autocorrelation exhibits more than for one lag in most of the wavelet decomposition components as well as for different combinations, for example, the A7 and each detail component with A7 decomposing from the monthly streamflow series via DWT (see Figure 9). This is why the two modified MK tests (MK1998 and MKDD) that consider full serial correlation structure were employed in this study. As shown in Table 4, the MK1998 and MKDD for autocorrelation performed well in most series with high ACFs. However, given the situation that the slope $\beta$ of the trend approaches zero, such as for D2, D3 and D4, the two modified MK tests are not robust even though the existing trend can be approximated by linear trend. Since this situation mainly occurs in the individual detail component and it has little influence on each detail component with the approximation, it is not considered and explored in later trend analysis. In addition, the original MK test performs worse when the ACF is high, as expected. However, the original MK test is still powerful in the case that the slope $\beta$ of the trend approaches zero even though the ACFs of the series are extremely high $(r>0.9)$. This could explain why the original MK test was applied in this study.

Table 4. Slope $\beta$ (computed by TSA), Lag-1 ACFs, Mann-Kendall values (three MK tests) and energy of monthly mean streamflow series: original data, detail components (D1-D7), approximations (A7) and a set of combinations of the details and their respective approximations. $C_{0}$ is the correlation coefficients between the decomposition combinations and the original series.

\begin{tabular}{cccccccc}
\hline Series & Slope $(\beta)$ & ACF & MK & MK1998 & MKDD & $C_{\mathbf{0}}$ & Energy \\
\hline Original & -0.0027 & 0.399 & $-13.179 *$ & $-5.503 *$ & $-4.025^{*}$ & - & 69,705 \\
A7 & -0.0103 & 0.995 & $-34.542 *$ & $-5.855^{*}$ & $-9.761 *$ & 0.212 & 14,476 \\
D1 & -0.0003 & -0.437 & -0.647 & -0.849 & -0.942 & 0.556 & 18,159 \\
D2 & 0 & 0.338 & -0.066 & -0.171 & -0.122 & 0.385 & 8783 \\
D3 & 0.0003 & 0.83 & 0.366 & 0.444 & 0.337 & $\mathbf{0 . 6 1 1}$ & $\mathbf{2 2 , 0 1 1}$ \\
D4 & 0.0003 & 0.932 & 0.614 & 1.485 & $3.356 *$ & 0.252 & 4569 \\
D5 & -0.0003 & 0.98 & -1.287 & -1.016 & -0.806 & 0.171 & 1895 \\
D6 & -0.0002 & 0.995 & -0.797 & -0.579 & -0.911 & 0.126 & 985 \\
D7 & 0.0006 & 0.999 & $3.682 *$ & 1.307 & $2.145 *$ & 0.023 & 348 \\
D1 + A7 & -0.0102 & -0.227 & $-16.555^{*}$ & $-15.260 *$ & $-20.989 *$ & 0.595 & 32,641 \\
D2 + A7 & -0.0103 & 0.512 & $-\mathbf{1 5 . 8 3 0 *}$ & $-12.121 *$ & $-15.987 *$ & 0.438 & 23,381 \\
D3 + A7 & -0.0098 & 0.852 & $-\mathbf{1 0 . 2 6 2} *$ & $-9.374 *$ & $-\mathbf{7 . 9 6 3} *$ & $\mathbf{0 . 6 4 5}$ & $\mathbf{3 6 , 6 9 6}$ \\
D4 + A7 & -0.0098 & 0.964 & $-18.084 *$ & $-12.563 *$ & $-16.646 *$ & 0.333 & 18,692 \\
D5 + A7 & -0.0101 & 0.984 & $-23.363 *$ & $-10.236^{*}$ & $-15.233 *$ & 0.275 & 16,204 \\
D6 + A7 & -0.0098 & 0.993 & $-25.500 *$ & $-8.628^{*}$ & $-11.843 *$ & 0.244 & 15,522 \\
\hline
\end{tabular}

Notes: * Indicates significant trend values at $\alpha=5 \%$; the most effective periodic components for trends are indicated in bold format. 


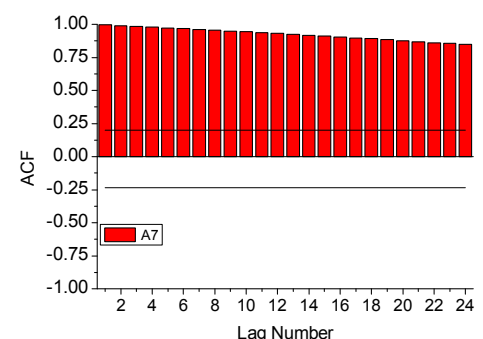

(a)

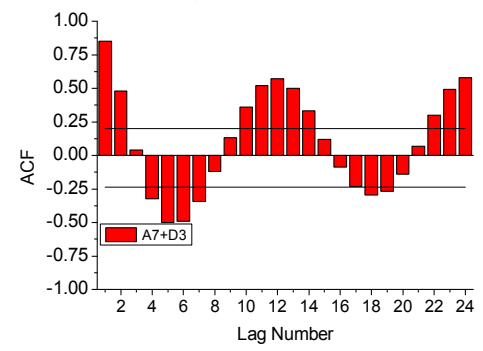

(d)

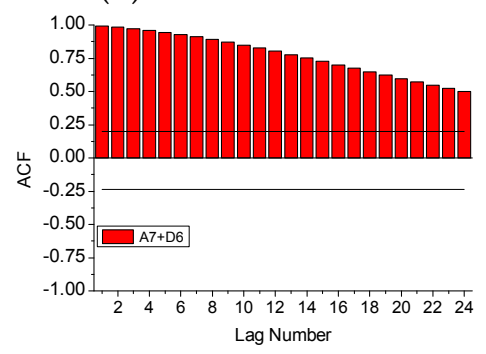

(g)

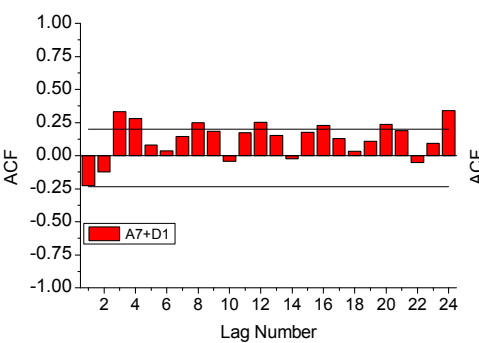

(b)

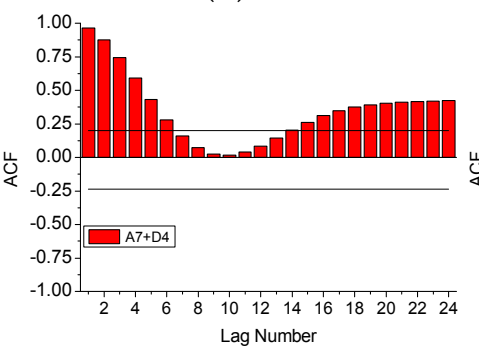

(e)

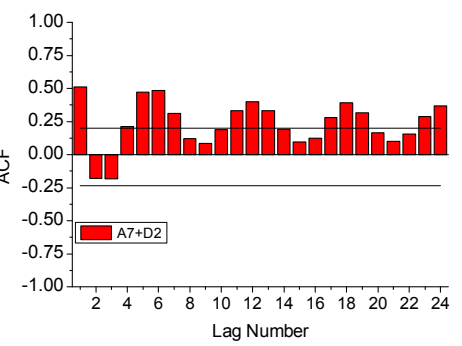

(c)

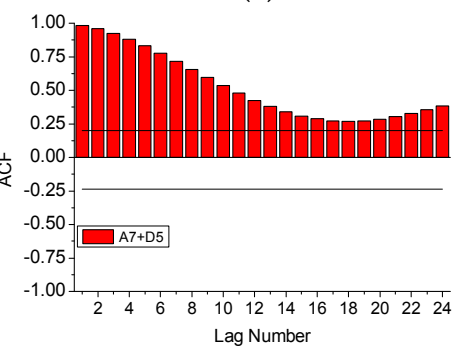

(f)

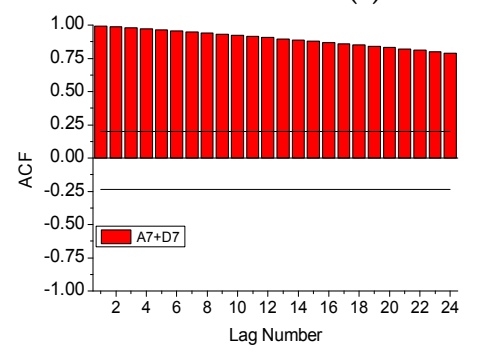

(h)

Figure 9. The correlograms of A7 and each detail component with A7 decomposing from the monthly streamflow series via DWT. The upper and lower solid lines represent the confidence intervals (95\% confidence level). (a) A7; (b) A7 + D1; (c) A7 + D2; (d) A7 + D3; (e) A7 + D4; (f) A7 + D5; (g) A7 + D6; (h) A7 + D7.

In Table 4, the most effective periodic components vary from one MK test to another. The original MK, MK1998 and MKDD tests indicate that D2 and D3; D7; D3 are responsible for the real trend in the monthly mean streamflow, respectively. Based on further analysis of different details of D1-D6 and the combination of $\mathrm{D} 7+\mathrm{A} 7$, all three $\mathrm{MK}$ tests indicated that the $\mathrm{MK} Z$ value approached the $\mathrm{MK} Z$ value of the original series only under the combination of D7 + A7 and D3, which means the D7 is not the dominant periodic component for the trend. It is interesting to find that the total energy of the detail components (D1-D7) and the approximation (A7) approach the energy of the original series; and the highest energy of the periodic components is D3, as presented in Table 4. It also can be been that the change of $C_{0}$ was basically the same with the change of energy in detail component combinations. D3 with A5, which has the highest energy, also has the highest $C_{0}(0.645)$. In addition, two sequential MK (the original MK and MKDD) graphs of the different periodic components with approximations corresponding to the original series of the monthly mean streamflow are shown in Figure 10, in which the trend line of D3 with A7 is most similar to the trend line of the original series. This evidence proves that D3 is the dominant periodic component for the observed trend in the monthly mean streamflow.

\subsubsection{Monthly Total Precipitation}

As shown in Table 5, all of the original MK, MK1998 and MKDD tests suggest that D3 is the dominant periodic component in affecting the trend of the monthly total precipitation series in Table 5 . 
The DW3 has the highest energy and $C_{0}$, which corresponds with the results of the monthly mean streamflow. Three sequential MK graphs of the different periodic components with respect to the original series of the monthly total precipitation are shown in Figure 11, in which the trend line of D3 with A6 is most similar to the trend line of the original series. It makes sense that D3 is the most effective periodic component for the real trend seen in the monthly total precipitation. It is clear that the dominant periodic components in the monthly precipitation and streamflow are consistent. In addition, MK1998 and MKDD tests were not applicable in the trend examination of D5 due to the negative values in the calculations of the correction factor $c f$ which can result in incorrect results. However, detailed are not explored in this study due to the relatively lesser impact on our results.

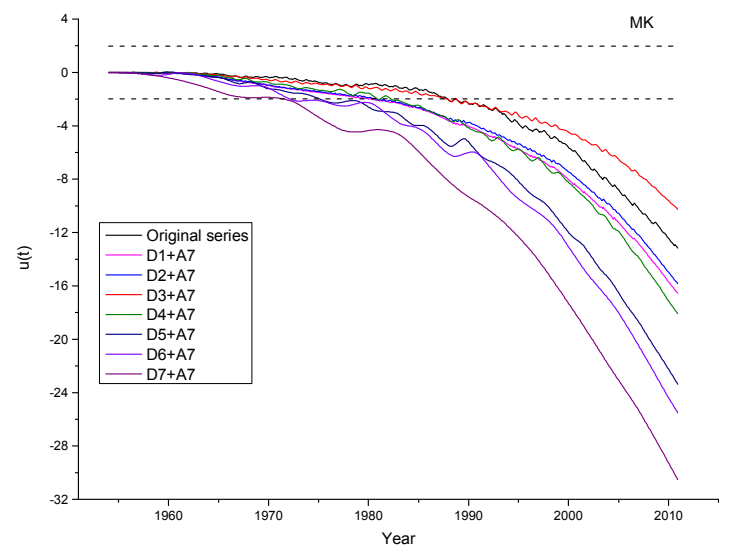

(a)

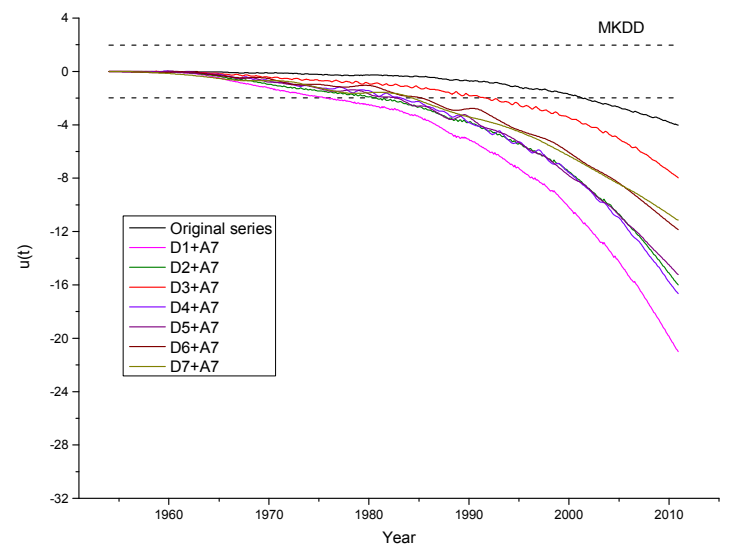

(b)

Figure 10. Two sequential Mann-Kendall (MK and MKDD) graphs of monthly streamflow series exhibiting the progressive trend lines of each detail component (with the addition of the approximation) with respect to the original series. The upper and lower dashed lines represent the confidence limits $(\alpha=5 \%)$. (a) MK; (b) MKDD.

Table 5. Lag-one ACFs, Mann-Kendall values (three MK tests) and energy of monthly total precipitation series: original data, details components (D1-D6), approximations (A6) and a set of combinations of the details and their respective approximations. $C_{0}$ is the correlation coefficients between the decomposition combinations and the original series.

\begin{tabular}{ccccccc}
\hline Series & ACF & MK & MK1998 & MKDD & $C_{\mathbf{0}}$ & Energy \\
\hline Original & 0.482 & 0.202 & 0.228 & 0.193 & - & $2,438,503$ \\
A6 & 0.999 & $-9.241 *$ & -1.510 & $-2.187 *$ & 0.071 & 828,972 \\
D1 & -0.626 & 0.317 & 0.692 & 0.526 & 0.434 & 305,735 \\
D2 & 0.369 & -0.168 & -0.270 & -0.190 & 0.455 & 336,637 \\
D3 & 0.852 & 0.325 & 0.385 & 0.313 & 0.716 & $\mathbf{8 4 0 , 5 6 1}$ \\
D4 & 0.954 & -0.047 & -0.084 & -0.269 & 0.25 & 98,838 \\
D5 & 0.987 & -1.789 & enable & enable & 0.13 & 25,058 \\
D6 & 0.997 & 0.682 & 0.465 & 0.696 & 0.08 & 12,201 \\
D1 + A6 & -0.581 & -1.748 & -1.841 & $-2.013 *$ & 0.44 & $1,134,729$ \\
D2 + A6 & 0.385 & -1.042 & -0.938 & -0.986 & 0.461 & $1,168,091$ \\
D3 + A6 & 0.853 & $-\mathbf{0 . 3 3 6}$ & $-\mathbf{0 . 3 3 7}$ & $-\mathbf{0 . 3 0 9}$ & $\mathbf{0 . 7 2}$ & $\mathbf{1 , 6 6 3 , 8 0 5}$ \\
D4 + A6 & 0.958 & -1.512 & -0.899 & -1.581 & 0.26 & 928,184 \\
D5 + A6 & 0.989 & $-5.125 *$ & -1.716 & $-2.319 *$ & 0.148 & 854,880 \\
D6 + A6 & 0.997 & $-4.703 *$ & -1.178 & -1.892 & 0.108 & 839,865 \\
\hline
\end{tabular}

Notes: ${ }^{*}$ Indicates significant trend values at $\alpha=5 \%$; the most effective periotic components for trends are indicated in bold format. 


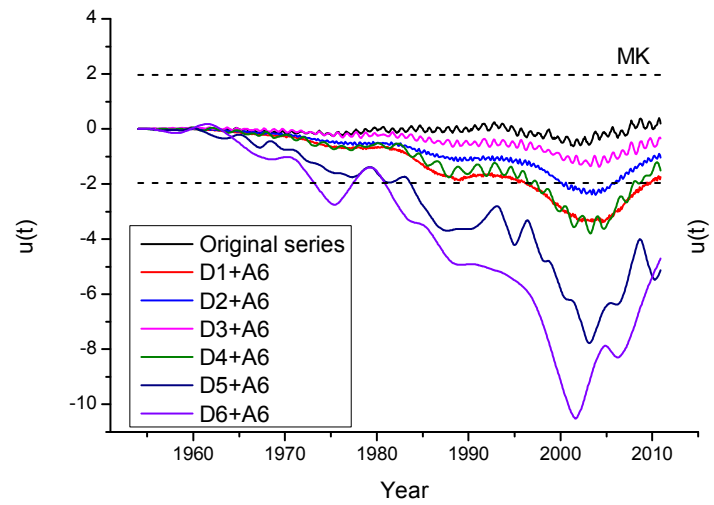

(a)

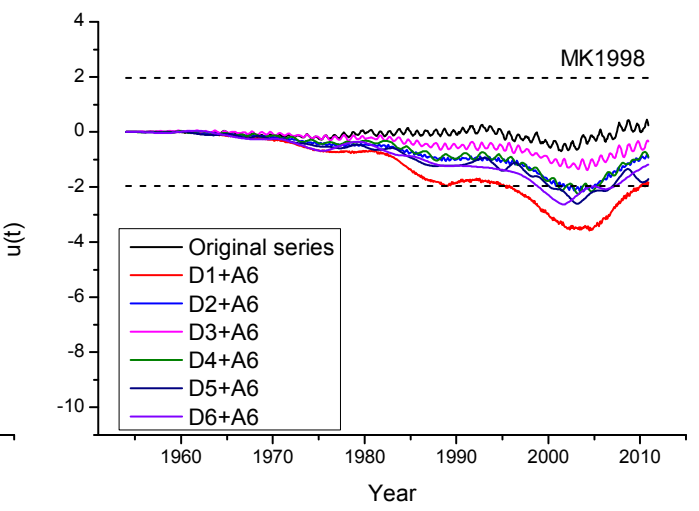

(b)

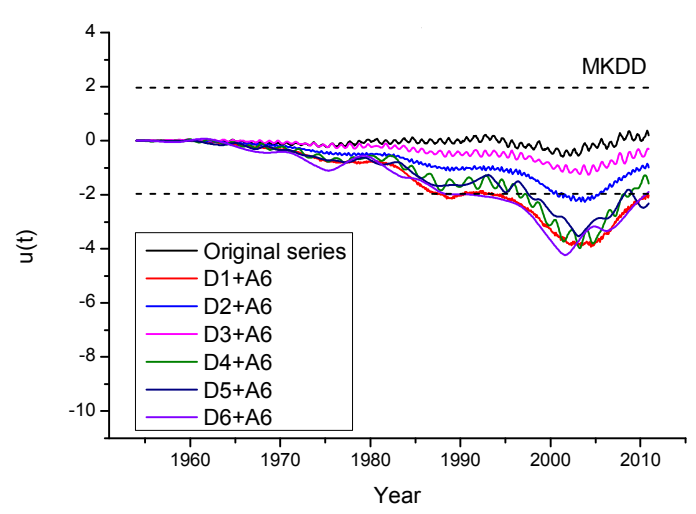

(c)

Figure 11. Three sequential Mann-Kendall graphs of monthly total precipitation series exhibiting the progressive trend lines of each detail component (with the addition of the approximation) with respect to the original series. The upper and lower dashed lines represent the confidence limits $(\alpha=5 \%)$. (a) MK; (b) MK1998; (c) MKDD.

\subsection{Decomposition and Analysis of Seasonal Data}

The seasonal mean streamflow and total precipitation series were both decomposed into four detail components and one approximation. D1, D2, D3 and D4 represent the 6-month, 12-month, 24-month and 48-month fluctuations, respectively. The A4 represents the approximation components at the fourth level of decomposition. The D2 component in the seasonal series decomposition represents the annual (12-month) periodicity which is very useful in confirming whether or not the annual cycles can explain the trends found in the flow and the precipitation series.

\subsubsection{Seasonal Mean Streamflow Series}

In Table 6, the original MK, MK1998 and MKDD tests indicate that D1 and D2; D1; D1 are the dominant periodic components in influencing the real trend in the seasonal mean streamflow series, respectively. As shown in Table 6, the DW1 has the highest energy and $C_{0}$ in the periodic components. Three sequential MK graphs of the seasonal mean streamflow are presented in Figure 12, and the trend line of D1 with A4 is most harmonious with the trend line of the original series. Obviously, D1 is the most effective periodic component for the real trend observed in the seasonal streamflow series. 
Table 6. Lag-1 ACFs, Mann-Kendall values and energy of seasonal mean streamflow series: original data, details components (D1-D4), approximations (A4) and a set of combinations of the details and their respective approximations. $C_{0}$ is the correlation coefficients between the decomposition combinations and the original series.

\begin{tabular}{ccccccc}
\hline Data & ACF & MK & MK1998 & MKDD & $\boldsymbol{C}_{\mathbf{0}}$ & Energy \\
\hline Original & 0.065 & $-7.624^{*}$ & $-4.055^{*}$ & $-3.188^{*}$ & - & 14,100 \\
A4 & 0.969 & $-17.946^{*}$ & $-8.343^{*}$ & $-16.597^{*}$ & 0.313 & 4878 \\
D1 & -0.359 & 1.5 & 0.772 & 0.571 & $\mathbf{0 . 7 6 5}$ & 6040 \\
D2 & 0.205 & 0.56 & 0.993 & 0.677 & 0.449 & 2497 \\
D3 & 0.745 & 0.044 & 0.1 & 0.059 & 0.246 & 491 \\
D4 & 0.952 & 1.557 & 1.57 & 1.886 & 0.191 & 477 \\
D1 + A4 & -0.131 & $-\mathbf{6 . 5 6 2} *$ & $-3.633 *$ & $-\mathbf{2 . 6 5 1} *$ & $\mathbf{0 . 8 2 2}$ & $\mathbf{1 1 , 0 3 2}$ \\
D2 + A4 & 0.464 & $-\mathbf{8 . 9 2 8} *$ & $-8.132 *$ & $-7.344 *$ & 0.552 & 7293 \\
D3 + A4 & 0.869 & $-13.844^{*}$ & $-7.722 *$ & $-8.074 *$ & 0.39 & 5462 \\
D4 + A4 & 0.947 & $-13.443 *$ & $-9.512 *$ & $-12.182 *$ & 0.393 & 5036
\end{tabular}

Notes: ${ }^{*}$ Indicates significant trend values at $\alpha=5 \%$; the most effective periotic components for trends are indicated in bold format.

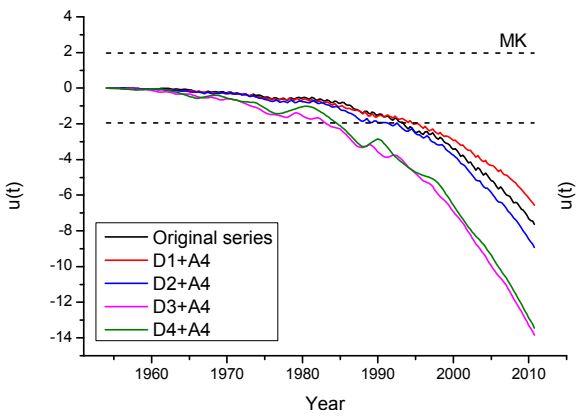

(a)

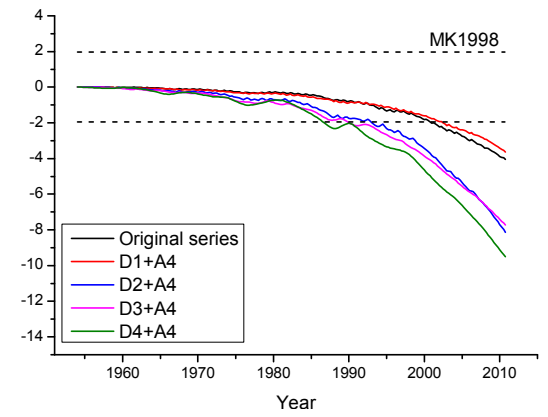

(b)

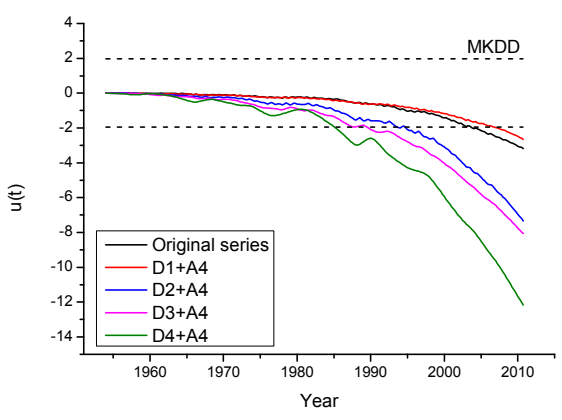

(c)

Figure 12. Three sequential Mann-Kendall graphs of seasonal mean streamflow series exhibiting the progressive trend lines of each detail component (with the addition of the approximation) with respect to the original series. The upper and lower dashed lines represent the confidence limits $(\alpha=5 \%)$.

(a) MK; (b) MK1998; (c) MKDD.

\subsubsection{Seasonal Total Precipitation Series}

As shown in Table 7, the original MK, MK1998 and MKDD tests indicate that D1 and D2; D1; D1 are the most influential components in affecting the real trend in the seasonal mean streamflow series, respectively. The sequential MK analysis of the seasonal total precipitation is shown in Figure 13, the trend line of D1 with A4 is most similar to the trend line of the original series. The original sequential MK graph also argues that D2 is the most influential periodic component for the trend. As can be seen in Table 7, the energy of D1 and D2 accounted for 17\% and 33\% of the total energy of the original sequence, respectively, which accounted for most of the total energy of details (92\%), and the higher 
$\mathrm{C}_{0}$ and energy indicate that D1 and D2 are probably the dominant periodicities. Further analysis was conducted and results showed that the energy of D1 + D2 + A4 accounted for $96 \%$ of the energy of the original series while the correlation coefficient $C_{0}$ of D1 $+\mathrm{D} 2+\mathrm{A} 4$ and the corresponding original series was up to 0.961 (Table 7). The results from all three MK tests show that the MK values of the $\mathrm{D} 1+\mathrm{D} 2+\mathrm{A} 4$ and the MK values of the original series are very close to each other. Apparently, D1 and $\mathrm{D} 2$ are the dominant periodic component for the trend of the seasonal total precipitation. It is important to say that the energy of the detail component combinations is a very important index to indicate the most effective components. In addition, D2, which represented the annual (12-month) periodicity in the seasonal time and was considered as the most dominant periodic component, $t$ indicating that annual cycles can explain the trends found in streamflow.

Table 7. Lag-one ACFs, Mann-Kendall values and energy of seasonal total precipitation series: original data, details components (D1-D4), approximations (A4) and a set of combinations of the details and their respective approximations. $C_{0}$ is the correlation coefficients between the decomposition combinations and the original series.

\begin{tabular}{ccccccc}
\hline Data & ACF & MK & MK1998 & MKDD & $\boldsymbol{C}_{\mathbf{0}}$ & Energy \\
\hline Original & -0.051 & 0.168 & 0.086 & 0.067 & - & 600,926 \\
A4 & 0.988 & $-5.513^{*}$ & -1.902 & $-3.115^{*}$ & 0.11 & 277,514 \\
D1 & -0.507 & -0.072 & -0.050 & -0.033 & 0.556 & 100,382 \\
D2 & 0.055 & -0.143 & -1.107 & -0.955 & $\mathbf{0 . 7 8 3}$ & 196,786 \\
D3 & 0.791 & -0.129 & -0.139 & -0.116 & 0.243 & 20,315 \\
D4 & 0.948 & -0.446 & -0.479 & -0.542 & 0.116 & 4836 \\
D1 + A4 & -0.445 & $-\mathbf{1 . 1 0 6}$ & $-\mathbf{0 . 7 2 7}$ & $-\mathbf{0 . 5 0 1}$ & 0.567 & 376,755 \\
D2 + A4 & 0.075 & $-\mathbf{0 . 9 2 0}$ & $-2.745^{*}$ & $-4.076^{*}$ & $\mathbf{0 . 7 9}$ & $\mathbf{4 7 5 , 7 1 9}$ \\
D3 + A4 & 0.819 & -1.865 & -1.131 & -1.171 & 0.268 & 297,078 \\
D4 + A4 & 0.959 & $-3.744^{*}$ & -1.779 & $-2.304^{*}$ & 0.161 & 281,563 \\
D1 + D2 + A4 & -0.126 & $\mathbf{0 . 0 5}$ & $\mathbf{0 . 0 2 5}$ & $\mathbf{0 . 0 1 9}$ & $\mathbf{0 . 9 6 1}$ & $\mathbf{5 7 8 , 0 5 6}$
\end{tabular}

Notes: ${ }^{*}$ Indicates significant trend values at $\alpha=5 \%$; the most effective periotic components for trends are indicated in bold format.

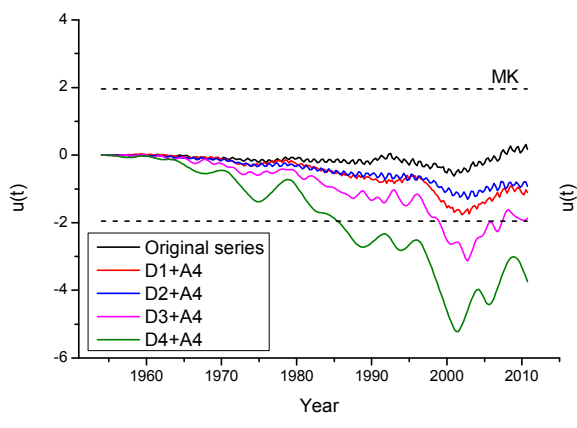

(a)

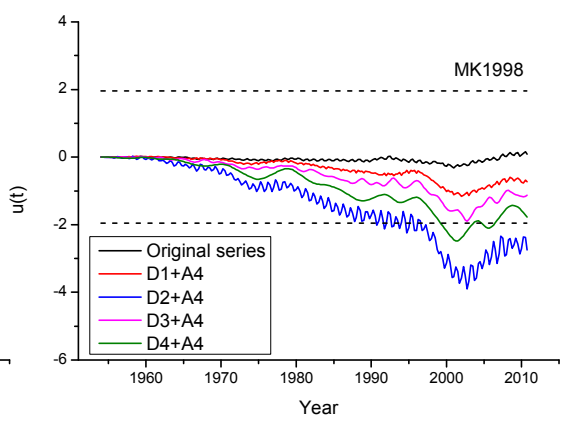

(b)

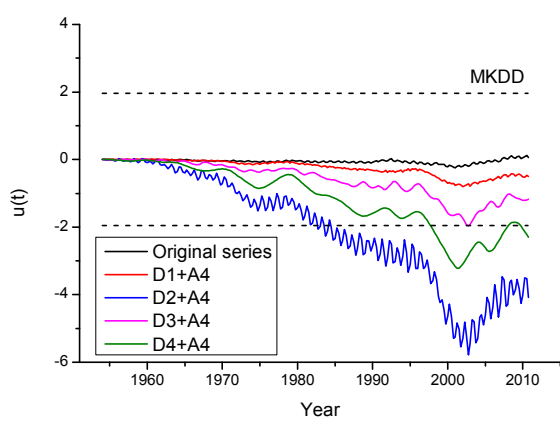

(c)

Figure 13. Three sequential Mann-Kendall graphs of seasonal total precipitation series exhibiting the progressive trend lines of each detail component (with the addition of the approximation) with respect to the original series. The upper and lower dashed lines represent the confidence limits $(\alpha=5 \%)$. (a) MK; (b) MK1998; (c) MKDD. 


\subsection{Decomposition and Analysis of Annual Aata}

In order to obtain a more thorough trend analysis, the annual mean streamflow and total precipitation time series were decomposed into four and five levels, respectively, which correspond to 2-year, 4-year, 8-year and 16-year variations. The continuous wavelet transform (CWT) and the global wavelet spectra (GWS) were also employed to analyze the annual data so as to explain its time-frequency characteristics, perfectly.

\subsubsection{Periodicities of Annual Streamflow and Precipitation Data}

The CWT scalograms and the global wavelet spectra of the CWTs are shown in Figures 14 and 15 to illustrate the general periodic structure of the streamflow and precipitation time series. Light regions on the scalogram plot and peaks in the GWS figure indicate the effective periodic events.

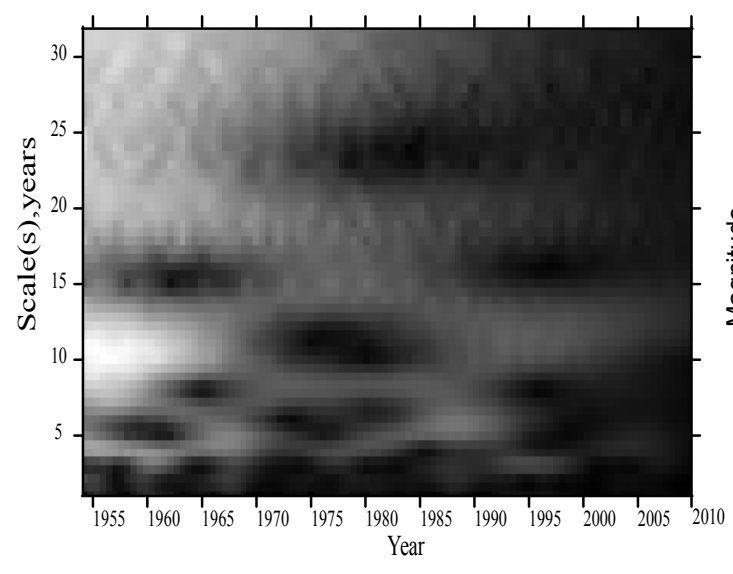

(a)

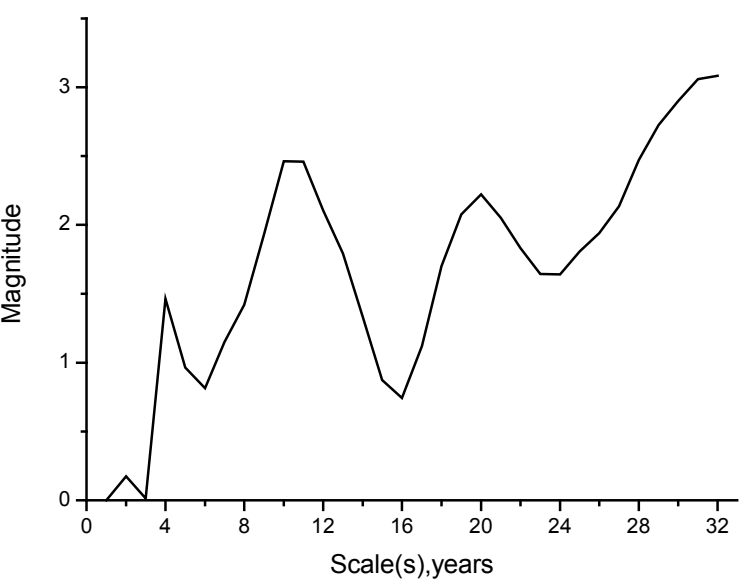

(b)

Figure 14. Continuous wavelet spectrum (a) and global wavelet spectrum (b) of the annual mean streamflow series.

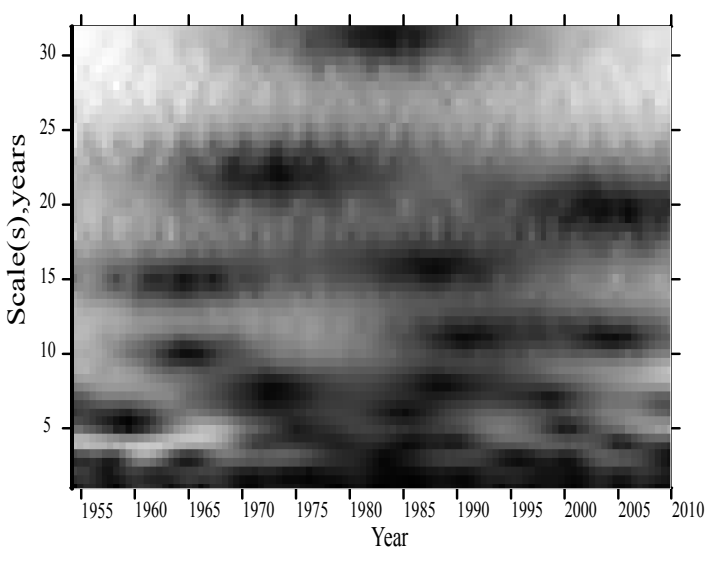

(a)

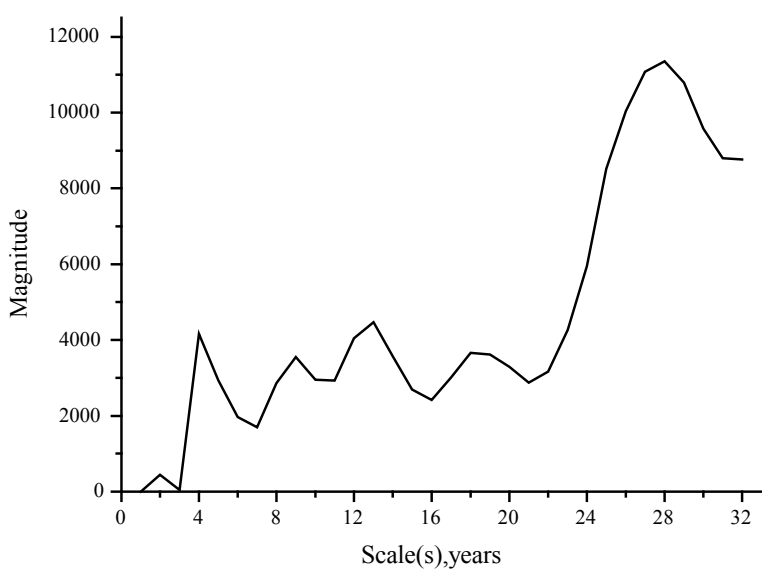

(b)

Figure 15. Continuous wavelet spectrum (a) and global wavelet spectrum (b) of the annual total precipitation series.

Figure 14 indicates that an obvious periodic event occurred for the annual streamflow with decreased trends intensity as periods ranged from 7-14 years, 17-24 years and 4-5 years, separately. The major periodicities can be cataloged to decadal events, including the intense 10- and 10-year 
scale events with peaks of GSW figures. Periodic events do not possess an overall property, with its continuity ending in the late 1990s, which can be explained by intensive human activities that probably resulted in a significant decrease and cutoff of streamflow [7]. Moreover, Figure 15 illustrated a decreased intensity of obvious periodic events for the annual precipitation as periods ranged from 25-30 years, 11-13 years, 4-5 years, 7-10 and 17-24 years, respectively. Similar to annual mean flow, the major periodicities of total precipitation are defined as decadal events, including the intense 28-year scale oscillation that is continues over time.

\subsubsection{Annual Mean Streamflow Series}

As shown in Table 8, the D1; D1,D3 and D4; D1 and D4 are the dominant periodic components for the real trend in the annual mean streamflow suggested by the original MK, MK1998 and MKDD test, respectively. D1 had the highest $C_{0}$ as well as the highest energy which implied that D1 might be the most influential periodic component for the trend. The sequential MK analysis of the annual mean streamflow is exhibited in Figure 16, the trend line of D1 with A4 approaches to the trend line of the original series, suggested by three MK tests. The sequential MK graphs tests also indicate that D3 (MK1998) and D4 (MK1998 and MKDD) could be the most effective periodic component for the trend found in the annual mean streamflow series. The reason why the original sequential MK test does not suggest that D4 is the dominant periodicity is that D4 with A4 has a very high autocorrelation coefficient (see Table 8) (the presence of the positive autocorrelation will overestimate the significance of trends). In addition, it is vital to note that decadal events are the major periodicities found in the CWT and GWS, which makes sense that D3 and D4 represent the decadal events found in the CWT figure and are the most effective periodic components. Therefore, D1, D3 and D4 are the most dominant periodic components for the trend in the annual mean streamflow.

Table 8. Lag-one ACFs, Mann-Kendall values and energy of annual mean streamflow series: original data, detail components (D1-D4), approximations (A4) and a set of combinations of the details and their respective approximations. $C_{0}$ is the correlation coefficients between the decomposition combinations and the original series.

\begin{tabular}{ccccccc}
\hline Data & ACF & MK & MK1998 & MKDD & $\boldsymbol{C}_{\mathbf{0}}$ & Energy \\
\hline Original & 0.166 & $-5.239 *$ & $-5.239 *$ & $-5.239^{*}$ & - & 1528 \\
A4 & 0.948 & $-9.823 *$ & $-5.058^{*}$ & $-8.497^{*}$ & 0.6 & 1184 \\
D1 & -0.618 & 0.145 & 0.208 & 0.151 & $\mathbf{0 . 5 6 2}$ & $\mathbf{2 2 0}$ \\
D2 & 0.322 & 0.048 & 0.101 & 0.088 & 0.45 & 149 \\
D3 & 0.818 & -0.805 & -0.882 & -1.295 & 0.252 & 18 \\
D4 & 0.903 & 0.296 & 0.212 & 0.215 & 0.049 & 18 \\
D1 + A4 & 0.18 & $-\mathbf{5 . 8 3 1} *$ & $-\mathbf{5 . 6 0 9}$ & $-\mathbf{4 . 6 4 5 *}$ & $\mathbf{0 . 8 2 7}$ & $\mathbf{1 3 9 0}$ \\
D2 + A4 & 0.653 & $-6.877 *$ & $-8.021 *$ & $-7.182 *$ & 0.753 & 1328 \\
D3 + A4 & 0.937 & $-8.791 *$ & $-\mathbf{5 . 5 9 5 *}$ & $-10.864 *$ & 0.629 & 1229 \\
D4 + A4 & 0.915 & $-10.925 *$ & $-\mathbf{5 . 9 8 0 *}$ & $-5.717 *$ & 0.631 & 1156 \\
\hline
\end{tabular}

Notes: * Indicates significant trend values at $\alpha=5 \%$; the most effective periotic components for trends are indicated in bold format.

\subsubsection{Annual Total Precipitation Series}

Based on previous trend analyses, MK1998 and MKDD effectively limited the influence of autocorrelation series trend analyses. However, in the analysis of D1, D2, D1 with A5, and D2 with A5, MK1998 and MKDD tests were still not applicable to trend analyses because there were negative values in the calculations of the correction factor $c f$ (see Table 9). Further studies are needed to improve the modified MK for complete autocorrelation structure on this issue, but this is not further explored in this study. 


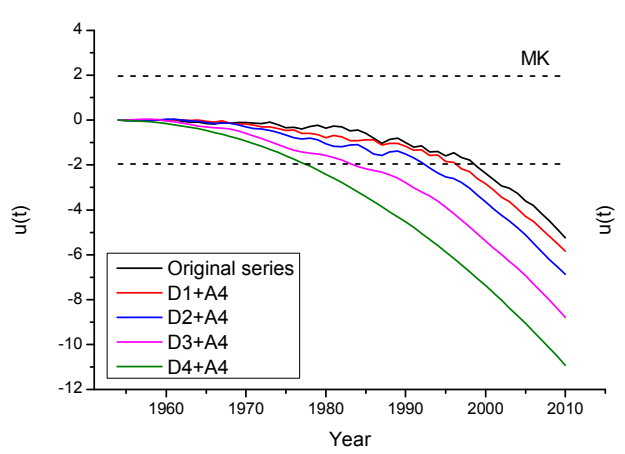

(a)

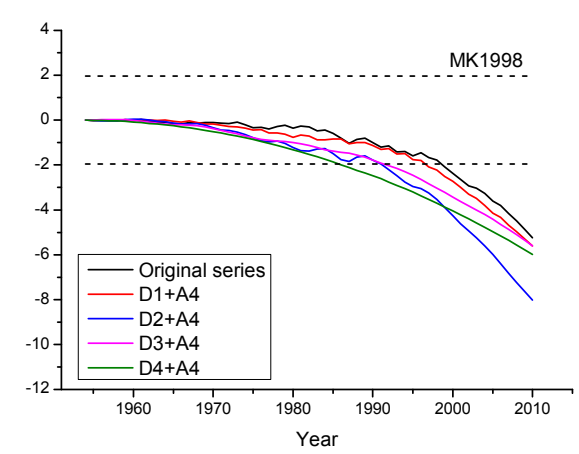

(b)

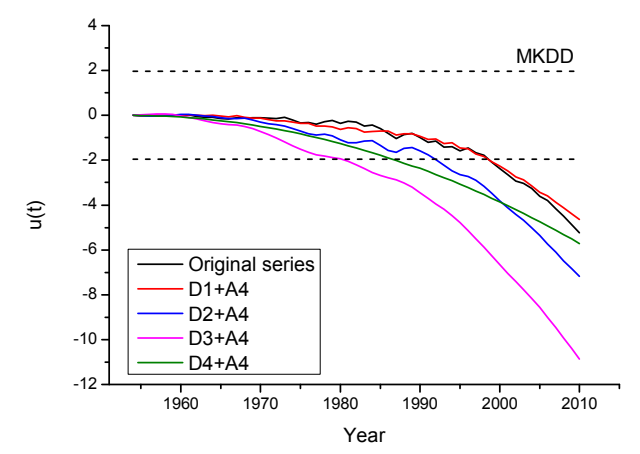

(c)

Figure 16. Three sequential Mann-Kendall graphs of annual mean streamflow series exhibiting the progressive trend lines of each detail component (with the addition of the approximation) with respect to the original series. The upper and lower dashed lines represent the confidence limits $(\alpha=5 \%)$.

(a) MK; (b) MK1998; (c) MKDD.

Table 9. Lag-one ACFs, Mann-Kendall values and energy of annual total precipitation: original data, detail components (D1-D5), approximations (A5) and a set of combinations of the details and their respective approximations. $C_{0}$ is the correlation coefficients between the decomposition combinations and the original series.

\begin{tabular}{ccccccccc}
\hline Data & ACF & MK & MK1998 & MKDD & MKDD1 & TFPW & $\boldsymbol{C}_{\mathbf{0}}$ & Energy \\
\hline Original & -0.266 & -0.902 & -1.286 & -1.344 & -1.196 & -0.984 & - & $10,820,675$ \\
A5 & 0.921 & -2.265 & -0.817 & -0.890 & -0.542 & $-10.994 *$ & -0.182 & $9,977,842$ \\
D1 & -0.691 & -0.186 & enable & enable & -0.426 & -0.434 & 0.807 & 616,764 \\
D2 & 0.27 & -0.103 & enable & enable & -0.079 & -0.379 & 0.493 & 208,741 \\
D3 & 0.796 & 0.062 & 0.092 & 0.105 & 0.022 & -0.213 & 0.292 & 87,441 \\
D4 & 0.938 & -0.778 & -0.529 & -0.836 & -0.162 & -2.072 & 0.201 & 17,038 \\
D5 & 0.93 & -4.619 & -1.636 & -1.530 & -1.163 & $-10.994 *$ & 0.228 & 38,918 \\
D1+A5 & -0.688 & -0.227 & enable & enable & -0.518 & 0.213 & 0.8 & $\mathbf{1 0 , 6 2 8 , 4 3 4}$ \\
D2+A5 & 0.276 & -0.172 & enable & enable & -0.130 & -0.516 & 0.479 & $10,148,639$ \\
D3+A5 & 0.793 & -0.062 & -0.089 & -0.101 & -0.022 & -1.095 & 0.272 & $10,078,044$ \\
D4+A5 & 0.944 & $-\mathbf{0 . 7 5 0}$ & $-\mathbf{0 . 6 3 2}$ & $-\mathbf{1 . 4 5 0}$ & -0.152 & $-2.141 *$ & 0.174 & $10,095,310$ \\
D5+A5 & 0.938 & $-5.032 *$ & $-\mathbf{1 . 8 3 4}$ & $-\mathbf{1 . 7 2 3}$ & -1.299 & $-10.994 *$ & 0.222 & $9,718,913$ \\
\hline
\end{tabular}

Notes: ${ }^{*}$ Indicates significant trend values at $\alpha=5 \%$; the most effective periotic components for trends are indicated in bold format.

To avoid the compatibility issue that results from MK1998 and MKDD in the trend analysis of D1 with A5 and D2 with D5, which may ignore that D1 and D2 are the possible dominant periodic component for the trend found in the annual total precipitation, the MKDD1 and TFPW tests were used to conduct trend examinations. As displayed in Table 9, the results of the MKDD1 and TFPW 
indicate that D1 with A5 and D2 with A5 are not the dominant periodic components. As discussed above, the MKDD1 and TFPW tests are not overall powerful, therefore, they are not applied, to make sure which detail component is the most effective periodic component for the observed trend.

The D4; D4 and D5; D4 and D5 are the dominant periodic components for the real trend of the annual mean streamflow suggested by the original MK, MK1998, and MKDD, separately. The sequential MK analysis of the annual total precipitation is presented in Figure 17, the trend line of D4 with A5 does not match well with the trend line of the original series. D4 has the lowest $C_{0}$, which also indicates that the difference of D4 with A5 and the original series is high. Therefore, D4 is not considered to be the most effective component in influencing the trend. This also illustrates that when analyzing the dominant periodic component for the trend, both MK values and their sequential MK graph should be taken into consideration. In addition, MK1998 and MKDD also indicate that D5 is the most effective periodic component for the trend found in the annual total precipitation series. It is worth mentioning that the intense 28-year scale oscillation which is defined as a decadal event is found in the CWT and GWS, which figures out that D5 represents the decadal events found in the CWT figure and is the most influential periodic component. According to previous analysis, the combination of the periodic component and respective approximation with higher energy has more significant impacts on the trend of the observed series. From the results of trend assessment, D5 is the most effective periodic component for the observed trend, but it has the lowest energy. This might be due to the fact that the energy of A5 accounts for $92 \%$ of the energy of the annual total precipitation series while the energy of the detail components only account for about $8 \%$ of the total energy. There is no big energy difference among each detail component with A5. In this case, energy is no longer an important index to evaluate the most effective periodic component for the observed trends. To sum up, D5 is the most dominant periodic component for the trend in the total precipitation streamflow.

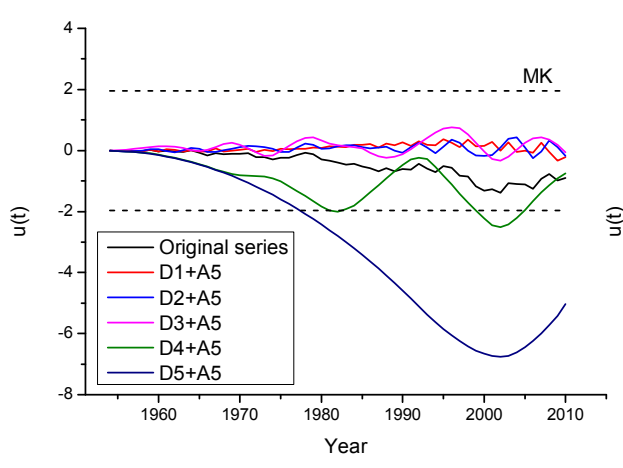

(a)

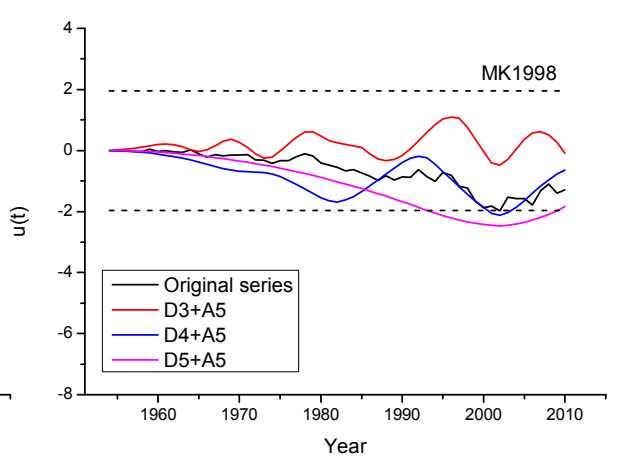

(b)

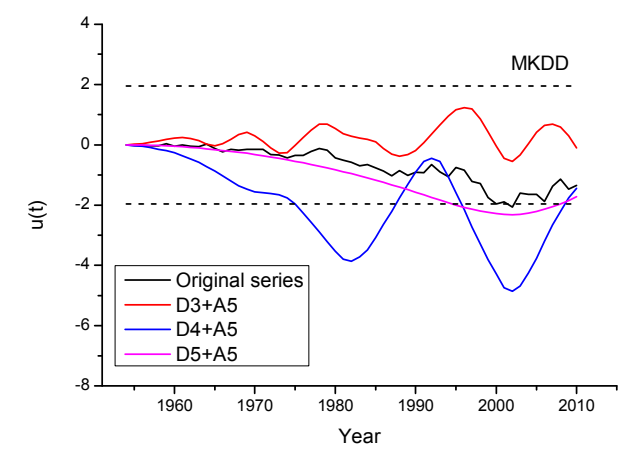

(c)

Figure 17. Three sequential Mann-Kendall graphs of annual total precipitation series exhibiting the progressive trend lines of each detail component (with the addition of the approximation) with respect to the original series. The upper and lower dashed lines represent the confidence limits $(\alpha=5 \%)$. (a) MK; (b) MK1998; (c) MKDD. 


\subsection{Factors Related to Precipitation and Streamflow Variations}

Previous trend analysis indicated that there are no significant trends in precipitation, while strong decreasing trends were found in streamflow. Precipitation variations have been closely associated with the increasing global temperature and El Niño/Southern Oscillation (ENSO) $[7,48,63]$. Baddoo et al. (2015) [48] proved that ENSO events influenced precipitation in Huangfuchuan basin, with El Niño corresponding to precipitation decline and La Niña to precipitation increment, with a semiannual to annual lag. Global temperature has been increasing since the 1980s and the climate aridity in Huangfuchuan basin has increased in the recent three decades [7]. It is found that the combination of climate change and human activities has resulted in significant decreasing streamflow, and intensive anthropogenic activities in the upper and middle reaches of the Yellow River basin, such as reservoirs, agricultural irrigation and soil and water conservation measures, account for more of this reduction $[7,49,53,63]$. Zhou et al. [7] found that the primary cause of streamflow reduction in Huangfuchuan was attributed to water diversion for irrigation in 1979-1998, and soil conversation measures in 1999-2006.

For the monthly, seasonal and annual mean streamflow series analysis, the common periodic components that were found to be the most influential for the observed trends are 8 months, 6 months and 2 years, as well as 8-16 years, separately. For the monthly, seasonal and annual total precipitation series analysis, the common periodic components seen as the most influential for the observed trends are 8 months, 6-12 months and 32 years, respectively. As can be seen, the different data types produced pretty different conclusions in terms of the most dominant periodicities for observed trends. The leading factors that impact the trends in the monthly and seasonal series in the Huangfuchuan watershed are intra-annual cycles (6-12 months), which may be associated with strong seasonal and annual cycles in the data. Studies indicated that shorter and discontinuous periodicities found in streamflow are likely influenced by human activities $[49,64]$. Therefore, the intra-annual periodic modes are also linked with anthropogenic activities. Inter-annual ( 2 and 8 years) and decadal (16 and 32 years) periodicities can be seen as the most influential components for the observed trends in annual series, and decadal events are the major periodicities. Baddoo et al. (2015) found that the correlation between precipitation in Huangfuchuan and ENSO events is at the 2-7 year periodicities. It is suggested that the effect of ENSO on precipitation will in turn affect the streamflow activities [65]. Li and Yang (2005) [66] found a correlation between precipitation and solar activities in the Yellow River basin at 9 and 11 years. The combination effects of solar activities and ENSO are found at 18-32 years [67]. Here, inter-annual periodicities are likely related to 2-7 year ENSO events and decadal periodic modes may be correlated to the combined effects of solar activities and ENSO cycles. Overall, multiple factors (e.g., ENSO, solar activities) are influencing the periodicities identified in precipitation and streamflow over the Huangfuchuan basin.

\section{Conclusions and Recommendations}

The wavelet transform and different MK tests were employed to investigate the possible trends and the basic structure of the trends in the mean streamflow and total precipitation in Huangfuchuan watershed. A comparative analysis of five different MK methods, including the original MK test and the modified MK tests with lag-one and full serial correlation, showed that consideration of only lag-1 autocorrelation (for TFPW and MKDD1) is not sufficient to remove all significant serial correlation in the data series. The results of the trend analysis also indicated the significant downward trends in all monthly, seasonal and annual mean streamflow series, but weak upward trends in monthly and seasonal total precipitation series and poor negative trends in the annual total precipitation series. Precipitation variation in Huangfuchuan basin has been closely linked to ENSO events [48]. The combined effects of human activities and climate change account for the significant decreasing streamflow, however, intensive anthropogenic activities are the major factors $[7,27,49,53,68]$.

The modified MK tests (MK1998 and MKDD) that consider full serial correlation structure performed better than the original MK and the modified test for lag- 1 autocorrelation (TFPW and 
MKDD1), because significant autocorrelations exhibit for more than just one lag in most of the wavelet decomposition components as well as for different combinations. But in the case that the slope $\beta$ of the trend approaches zero, the two modified MK tests are not robust even though the existing trend can be approximated by linear trend. The original MK test performs worse when the ACF is high, as expected. However, the original MK test is still powerful in the case that the slope $\beta$ of the trend approaches zero even though the ACFs of the series are extremely high ( $r>0.9$ ). Additionally, MK1998 and MKDD tests are not applicable to the analysis of monthly and annual total precipitation series, and this can be attributed to negative values of the correction factor $c f$. Further discussion is not explored here, since it had little influence on this study. But future studies are needed to improve the modified MK, with complete autocorrelation structure on this issue. In summary, this study suggests that the original MK test and the modified MK test for full serial correlation structure should be applied together to better analyze the trend in the hydrological time series and the wavelet decomposition components obtained from DWT.

Three criteria were explored to determine the most appropriate smooth mother wavelet, the decomposition levels and the extension mode in the DWT procedure. The result revealed that the criterion $E r$ based on the relative error of energy that is proposed in this study performed better in comparison to the other two criteria, $M A E$ and $e r$. Additionally, the usage of $E r$ is very convenient and is not influenced by the method itself compared to $e r$ (the effect of $e r$ is influenced by the MK test).

In addition to the MK $Z$ values and the sequential MK graphs, a new and powerful index, the energy of the hydrological time series, was proposed and successfully utilized in this study to confirm the dominant periodic components for the trends. Furthermore, this index is easy to apply and has few limits. However, it is important to note that if there is no significant energy difference among different detail components with respective approximation, energy is no longer the key index to indicate which detail components are the most effective periodic component for the observed trend. Overall, from the energy of the hydrological time series point of view, this not only provides a robust index to determine which periodic component is the dominant periodic component for the trend, but also explores a new way of analyzing the hydrologic time series.

Intra-annual periodicities (6-12 months) were found to be the most influential components in producing the trends in monthly and seasonal series, which may be related to strong seasonal and annual cycles in monthly and seasonal data and human activities $[49,64]$. In the CWT and GWS of the annual series, the periodicities located between 2- and 4-year scales are seen, but the major periodicities are decadal events. Inter-annual ( 2,4 and 8 years) and decadal (16 and 32 years) periodicities found in annual series are likely associated with 2-7-year ENSO cycles and the combination effects of 11-year solar activities and 2-7-year ENSO events, respectively [48,49,67]. Additionally, although streamflow in the Huangfuchuan basin has been greatly influenced by human activities, the long-term fluctuations (decadal events) exhibited in annual streamflow are still evident. This indicates that the long-term fluctuations in streamflow are more influenced by climate variabilities (e.g., ENSO cycles, solar activities). However, the combined effects of ENSO events and solar activities in streamflow have not been extensively explored to date, especially in the yellow River basin. Thus, further studies could incorporate some linkages between the streamflow and combined climatic variabilities. The above findings will contribute to not only analyzing the trends in the hydrological time series, but also water resource planning and management in the semi-arid or arid river watersheds of China.

Acknowledgments: The funding support for this research paper was provided by the National Natural Science Foundation of China (NSFC51209064 and NSFC51579067).

Author Contributions: Yiqing Guan and Danrong Zhang were primarily accountable for data collection and design and coordination of the study. Yuzhuang Chen and Guangwen Shao were responsible for data analysis, interpretation and writing of the paper.

Conflicts of Interest: The authors declare no conflict of interest. 


\section{References}

1. Stojković, M.; Ilić, A.; Prohaska, S.; Plavšić, J. Multi-temporal analysis of mean annual and seasonal stream flow trends, including periodicity and multiple non-linear regression. Water Resour. Manag. 2014, 28, 4319-4335. [CrossRef]

2. Yue, S.; Pilon, P.; Cavadias, G. Power of the Mann-Kendall and spearman's rho tests for detecting monotonic trends in hydrological series. J. Hydrol. 2002, 259, 254-271. [CrossRef]

3. Jones, P.D.; Lister, D.H.; Osborn, T.J.; Harpham, C.; Salmon, M.; Morice, C.P. Hemispheric and large-scale land-surface air temperature variations: An extensive revision and an update to 2010. J. Geophys. Res. Atmos. 2012, 117, 214-221. [CrossRef]

4. Rohde, R.; Curry, J.; Groom, D. Berkeley earth temperature averaging process. Geoinform. Geostat. Overv. 2013, 1. [CrossRef]

5. Huntington, T.G. Evidence of intensification of the global water cycle: Review and synthesis. J. Hydrol. 2006, 319, 83-95. [CrossRef]

6. Renner, M.; Bernhofer, C. Long term variability of the annual hydrological regime and sensitivity to temperature phase shifts in Saxony/Germany. Hydrol. Earth Syst. Sci. 2011, 15, 1819-1833. [CrossRef]

7. Zhou, Y.; Shi, C.; Fan, X.; Shao, W. The influence of climate change and anthropogenic activities on annual runoff of Huangfuchuan basin in northwest China. Theor. Appl. Clim. 2015, 120, 137-146. [CrossRef]

8. Mishra, A.K.; Singh, V.P. Changes in extreme precipitation in Texas. J. Geophys. Res. Atmos. 2010, 115, 1307-1314. [CrossRef]

9. Burn, D.H.; Mohammed, S.; Kan, Z. Detection of trends in hydrological extremes for Canadian watersheds. Hydrol. Process. 2010, 24, 1781-1790. [CrossRef]

10. Cong, Z.; Yang, D.; Gao, B.; Yang, H.; Hu, H. Hydrological trend analysis in the Yellow River basin using a distributed hydrological model. Water Resour. Res. 2009, 45, 335-345. [CrossRef]

11. Hu, Z.; Wang, L.; Wang, Z.; Hong, Y.; Zheng, H. Quantitative assessment of climate and human impacts on surface water resources in a typical semi-arid watershed in the middle reaches of the Yellow River from 1985 to 2006. Int. J. Climatol. 2015, 35, 97-113. [CrossRef]

12. Xu, H.; Taylor, R.G.; Xu, Y. Quantifying uncertainty in the impacts of climate change on river discharge in sub-catchments of the Yangtze and Yellow River basins, China. Hydrol. Earth Syst. Sci. 2011, 15, 333-344. [CrossRef]

13. Lettenmaier, D.P.; Wood, E.F.; Wallis, J.R. Hydro-climatological trends in the continental United States, 1948-88. J. Clim. 1994, 7, 586-607. [CrossRef]

14. Zhang, X.; Vincent, L.A.; Hogg, W.D.; Niitsoo, A. Temperature and precipitation trends in canada during the 20th century. Atmos. Ocean 2000, 38, 395-429. [CrossRef]

15. Zhang, X.; Harvey, K.D.; Hogg, W.D.; Yuzyk, T.R. Trends in canadian streamflow. Water Resour. Res. 2001, 37, 987-998. [CrossRef]

16. Birsan, M.V.; Molnar, P.; Burlando, P.; Pfaundler, M. Streamflow trends in Switzerland. J. Hydrol. 2005, 314, 312-329. [CrossRef]

17. Hannaford, J.; Buys, G. Trends in seasonal river flow regimes in the UK. J. Hydrol. 2012, 475, 158-174. [CrossRef]

18. Hannaford, J.; Buys, G.; Stahl, K.; Tallaksen, L.M. The influence of decadal-scale variability on trends in long European streamflow records. Hydrol. Earth Syst. Sci. 2013, 17, 2717-2733.

19. Burn, D.H.; Elnur, M.A.H. Detection of hydrologic trends and variability. J. Hydrol. 2002, 255, 107-122. [CrossRef]

20. Nalley, D.; Adamowski, J.; Khalil, B. Using discrete wavelet transforms to analyze trends in streamflow and precipitation in Quebec and Ontario (1954-2008). J. Hydrol. 2012, 475, 204-228. [CrossRef]

21. Bihrat, O.O.; Bayazit, M.C. The power of statistical tests for trend detection. Turk. J. Eng. Environ. Sci. 2003, 27, 247-251.

22. Partal, T.; Kucuk, M. Long-term trend analysis using discrete wavelet components of annual precipitations measurements in marmara region (Turkey). Phys. Chem. Earth 2006, 31, 1189-1200. [CrossRef]

23. Adamowski, K.; Prokoph, A.; Adamowski, J. Development of a new method of wavelet aided trend detection and estimation. Hydrol. Process. 2009, 23, 2686-2696. [CrossRef] 
24. Hamed, K.H.; Rao, A.R. A modified Mann-Kendall trend test for autocorrelated data. J. Hydrol. 1998, 204, 182-196. [CrossRef]

25. Yue, S.; Pilon, P.; Phinney, B.; Cavadias, G. The influence of autocorrelation on the ability to detect trend in hydrological series. Hydrol. Process. 2002, 16, 1807-1829. [CrossRef]

26. Yue, S.; Wang, C.Y. The Mann-Kendall test modified by effective sample size to detect trend in serially correlated hydrological series. Water Resour. Manag. 2004, 18, 201-218. [CrossRef]

27. Ishak, E.H.; Rahman, A.; Westra, S.; Sharma, A.; Kuczera, G. Evaluating the non-stationarity of Australian annual maximum flood. Hydrology 2013, 494, 134-145. [CrossRef]

28. Gautam, M.R.; Acharya, K. Streamflow trends in Nepal. Hydrol. Sci. J. 2012, 57, 344-357. [CrossRef]

29. Kumar, S.; Merwade, V.; Kam, J.; Thurner, K. Streamflow trends in indiana: Effects of long term persistence, precipitation and subsurface drains. J. Hydrol. 2009, 374, 171-183. [CrossRef]

30. Khaliq, M.N.; Ouarda, T.B.M.J.; Gachon, P.; Sushama, L.; St-Hilaire, A. Identification of hydrological trends in the presence of serial and cross correlations: A review of selected methods and their application to annual flow regimes of Canadian rivers. J. Hydrol. 2009, 368, 117-130. [CrossRef]

31. Daubechies, I. The wavelet transform, time-frequency localization and signal analysis. IEEE Trans. Inf. Theory 1990, 36, 961-1005. [CrossRef]

32. Torrence, C.; Compo, G.P. A practical guide to wavelet analysis. Bull. Am. Met. Soc. 1998, 79, 61-78. [CrossRef]

33. Wang, W.; Hu, S.; Li, Y. Wavelet transform method for synthetic generation of daily streamflow. Water Resour. Manag. 2011, 25, 41-57. [CrossRef]

34. Kulkarni, J.R. Wavelet analysis of the association between the southern oscillation and the Indian summer monsoon. Int. J. Climatol. 2000, 20, 89-104. [CrossRef]

35. Dai, X.; Wang, P.; Jifan, C. Multiscale characteristics of the rainy season rainfall and interdecadal decaying of summer monsoon in north China. Sci. Bull. 2003, 24, 2730-2734. [CrossRef]

36. Pišoft, P.; Kalvová, J.; Brázdil, R. Cycles and trends in czech temperature series using wavelet transforms. Int. J. Climatol. 2004, 24, 1661-1670. [CrossRef]

37. Zume, J.T.; Tarhule, A. Precipitation and streamflow variability in northwestern Oklahoma, 1894-2003. Phys. Geogr. 2006, 27, 189-205. [CrossRef]

38. Xu, J.; Chen, Y.; Li, W.; Ji, M.; Shan, D.; Hong, Y. Wavelet analysis and nonparametric test for climate change in Tarim River basin of Xinjiang during 1959-2006. Chin. Geogr. Sci. 2009, 4, 306-313. [CrossRef]

39. Partal, T. Wavelet transform-based analysis of periodicities and trends of Sakarya basin (Turkey) streamflow data. River Res. Appl. 2010, 26, 695-711. [CrossRef]

40. Adarsh, S.; Reddy, M.J. Trend analysis of rainfall in four meteorological subdivisions of southern India using nonparametric methods and discrete wavelet transforms. Int. J. Climatol. 2015, 35, 1107-1124. [CrossRef]

41. Hirsch, R.M.; Slack, J.R. A nonparametric trend test for seasonal data with serial dependence. Water Resour. Res. 1984, 20, 727-732. [CrossRef]

42. Sang, Y.F. A practical guide to discrete wavelet decomposition of hydrologic time series. Water Resour. Manag. 2012, 26, 3345-3365. [CrossRef]

43. Percival, D.B.; Walden, A.T. Wavelet Methods for Time Series Analysis; Cambridge University Press: Cambridge, UK, 2002; p. 359.

44. Popivanov, I.; Miller, R.J. Similarity search over time-series data using wavelets. In Proceedings of the 18 th International Conference on Data Engineering, San Jose, CA, USA, 26 February-1 March 2002; Agrawal, R., Dittrich, K., Ngu, A.H.H., Eds.; IEEE: San Jose, CA, USA, 2002; pp. 212-221.

45. Artigas, M.Z.D.; Elias, A.G.; Campra, P.F.D. Discrete wavelet analysis to assess long-term trends in geomagnetic activity. Phys. Chem. Earth 2006, 31, 77-80. [CrossRef]

46. Vonesch, C.; Blu, T.; Unser, M. Generalized daubechies wavelet families. IEEE Trans. Signal Process. 2007, 55, 4415-4429. [CrossRef]

47. Su, H.; Liu, Q.; Li, J. Alleviating border effects in wavelet transforms for nonlinear time-varying signal analysis. Adv. Electr. Comput. Eng. 2011, 11, 55-60. [CrossRef]

48. Baddoo, T.D.; Guan, Y.; Zhang, D.; Andam-Akorful, S.A. Rainfall variability in the Huangfuchuang watershed and its relationship with ENSO. Water 2015, 7, 3243-3262. [CrossRef] 
49. Zhao, G.; Tian, P.; Mu, X.; Jiao, J.; Wang, F.; Gao, P. Quantifying the impact of climate variability and human activities on streamflow in the middle reaches of the Yellow River basin, China. J. Hydrol. 2014, 519, 387-398. [CrossRef]

50. Tian, P.; Zhao, G.; Mu, X.; Wang, F.; Gao, P.; Mi, Z. Check dam identification using multisource data and their effects on streamflow and sediment load in a Chinese Loess Plateau catchment. J. Appl. Remote Sens. 2013, 7, 073697. [CrossRef]

51. Li, E.; Mu, X.; Zhao, G.; Gao, P.; Shao, H. Variation of runoff and precipitation in the Hekou-Longmen region of the Yellow River based on elasticity analysis. Sci. World J. 2014, 2014. [CrossRef] [PubMed]

52. Wen, Z.M.; Jiao, F.; Jiao, J.Y. Prediction and mapping of potential vegetation distribution in Yanhe River catchment in hilly area of Loess Plateau. J. Appl. Ecol. 2008, 19, 1897-1904.

53. Fu, G.; Chen, S.; Liu, C.; Shepard, D. Hydro-climatic trends of the Yellow River basin for the last 50 years. Clim. Chang. 2004, 65, 149-178. [CrossRef]

54. Coulibaly, P.; Burn, D.H. Wavelet analysis of variability in annual Canadian streamflows. Water Resour. Res. 2004, 40, 225-236. [CrossRef]

55. Chou, C.M. Applying multi-resolution analysis to differential hydrological grey models with dual series. J. Hydrol. 2007, 332, 174-186. [CrossRef]

56. Mallat, G. A theory for multiresolution signal decomposition: The wavelet representation. IEEE Trans. Pattern Anal. Mach. Intell. 1989, 11, 674-693. [CrossRef]

57. Douglas, E.M.; Vogel, R.M.; Kroll, C.N. Trends in floods and low flows in the United States: Impact of spatial correlation. J. Hydrol. 2000, 240, 90-105. [CrossRef]

58. Yue, S.; Wang, C.Y. Applicability of prewhitening to eliminate the influence of serial correlation on the Mann-Kendall test. Water Resour. Res. 2002, 38. [CrossRef]

59. Theil, H. A Rank-Invariant Method of Linear and Polynomial Regression Analysis; Springer: Amsterdam, The Netherlands, 1992; Volume 23, pp. 345-381.

60. Sen, P.K. Estimates of the regression coefficient based on kendall's tau. J. Am. Stat. Assoc. 1968, 63, 1379-1389. [CrossRef]

61. Matalas, N.C.; Langbein, W.B. Information content of the mean. J. Geophys. Res. 1962, 67, 3441-3448. [CrossRef]

62. Kharitonenko, I.; Zhang, X.; Twelves, S. A wavelet transform with point-symmetric extension at tile boundaries. IEEE Trans. Image Process. 2002, 11, 1357-1364. [CrossRef] [PubMed]

63. Wang, H.; Yang, Z.; Saito, Y.; Liu, J.P.; Sun, X. Interannual and seasonal variation of the Huanghe (Yellow River) water discharge over the past 50 years: Connections to impacts from enso events and dams. Glob. Planet. Chang. 2006, 50, 212-225. [CrossRef]

64. Zhang, Q.; Xu, C.-Y.; Jiang, T.; Wu, Y. Possible influence of enso on annual maximum streamflow of the Yangtze River, China. J. Hydrol. 2007, 333, 265-274. [CrossRef]

65. Prokoph, A.; Adamowski, J.; Adamowski, K. Influence of the 11 year solar cycle on annual streamflow maxima in southern Canada. J. Hydrol. 2012, 442-443, 55-62. [CrossRef]

66. Chunhui, L.; Zhifeng, Y. Relationship between solar activities and precipitation in the Yellow River basin. Meteorol. Mon. 2006, 31, 42-44.

67. Fu, C.; James, A.L.; Wachowiak, M.P. Analyzing the combined influence of solar activity and el niño on streamflow across southern Canada. Water Resour. Res. 2012, 48. [CrossRef]

68. Zhao, G.; Mu, X.; Tian, P.; Wang, F.; Gao, P. The variation of stream flow and sediment flux in the middle reaches of Yellow River over the past 60 years and the influencing factors. Resour. Sci. 2012, 34, 1070-1078.

(C) 2016 by the authors; licensee MDPI, Basel, Switzerland. This article is an open access article distributed under the terms and conditions of the Creative Commons by Attribution (CC-BY) license (http://creativecommons.org/licenses/by/4.0/). 